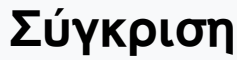

Tó 17 (2006)

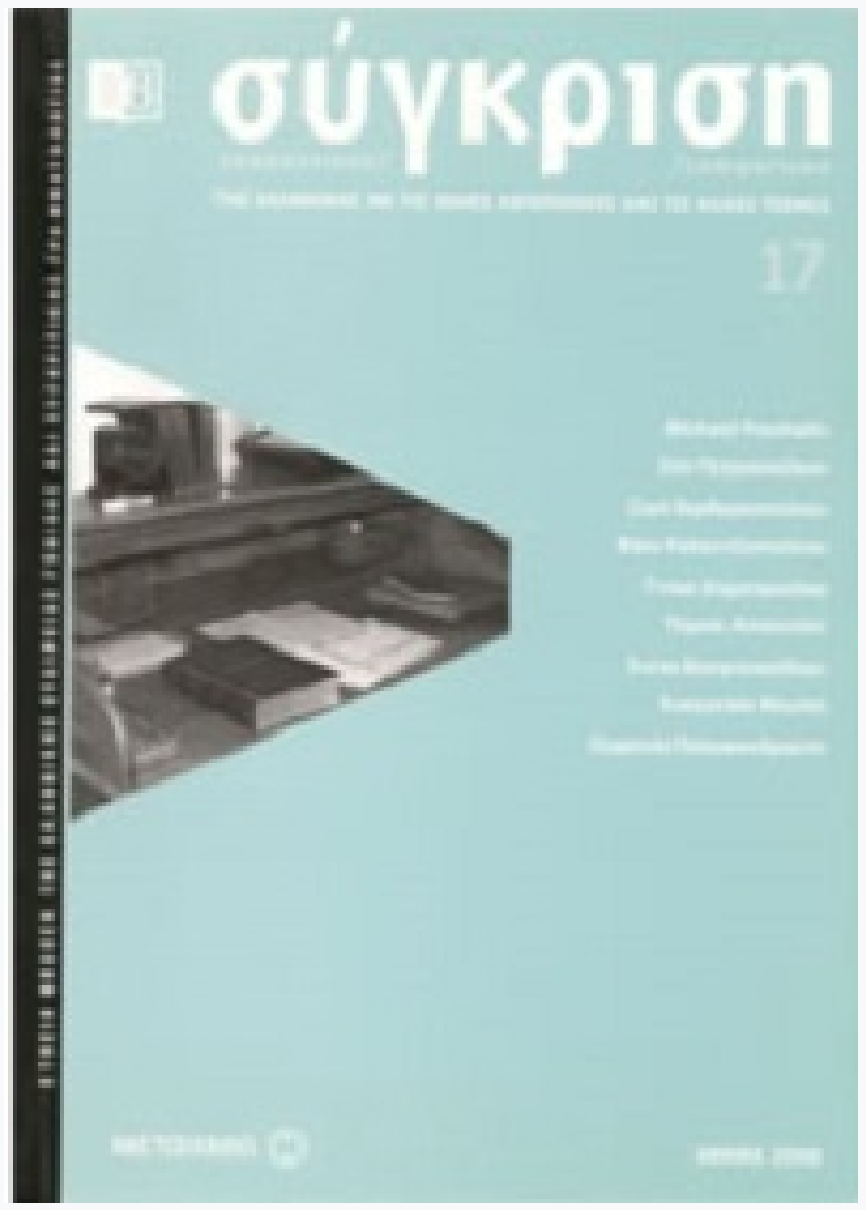

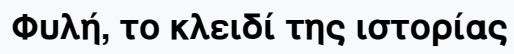

Avva Bouүıочкגíסоu

doi: $10.12681 /$ comparison.10217

Copyright @ 2016, Avva Bouүıuk $\lambda$ íoou

\section{(C) $10(0)$}

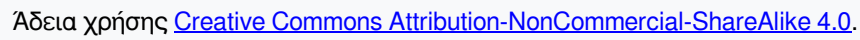

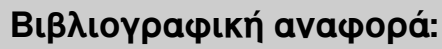

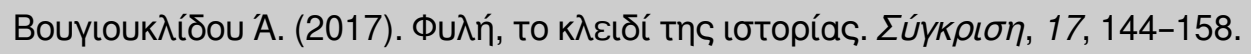

https://doi.org/10.12681/comparison.10217 


\section{ANNABOYTIOYKAIDOY}

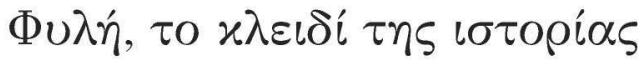

-

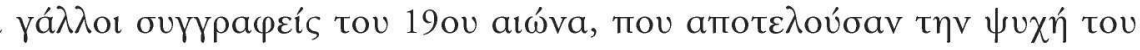

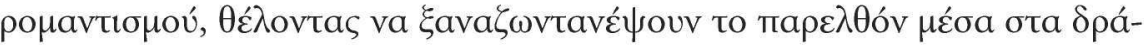

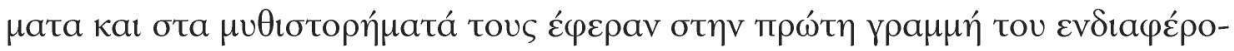

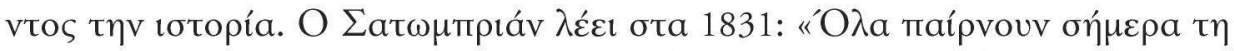

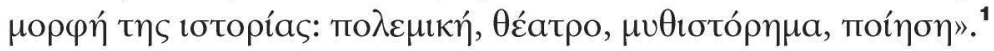

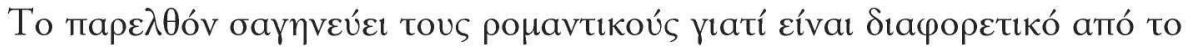

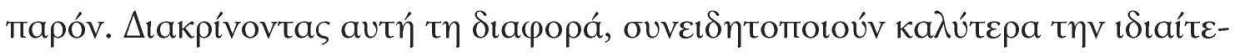

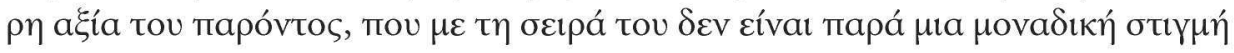

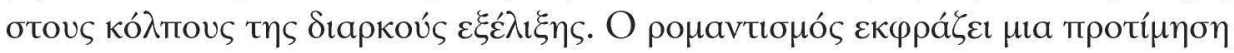

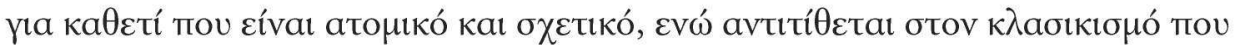

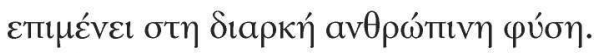

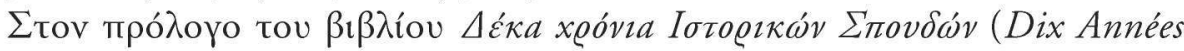

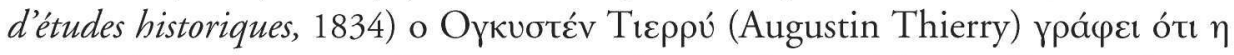

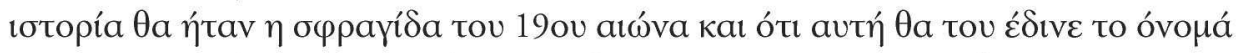

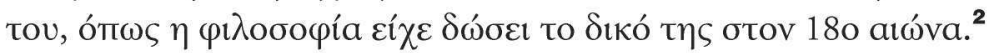

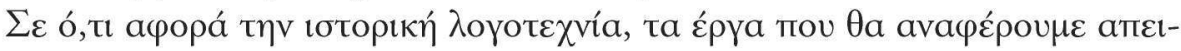

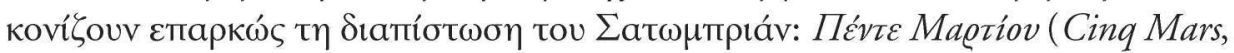

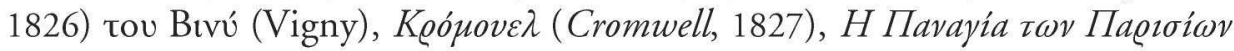

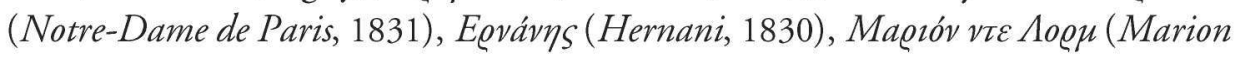

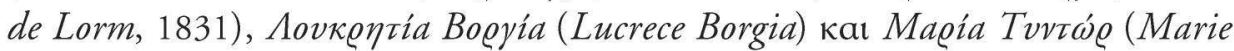

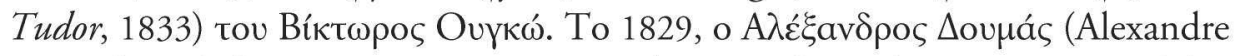

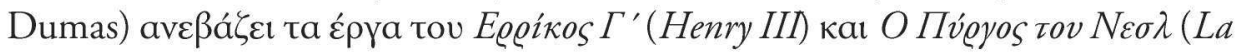

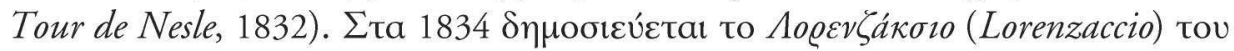

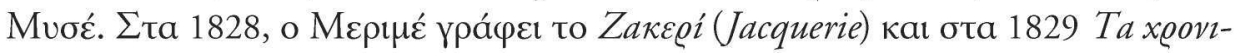

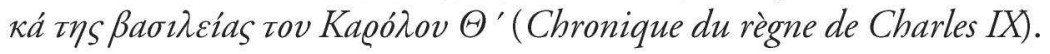

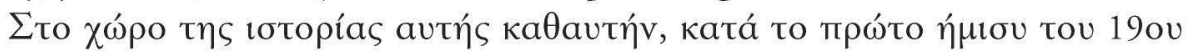

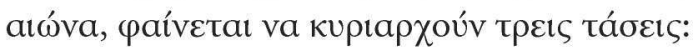

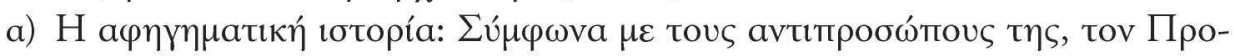

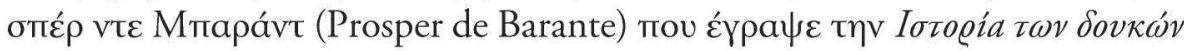

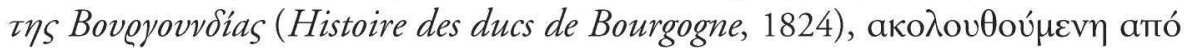

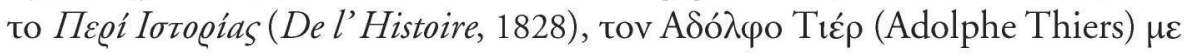




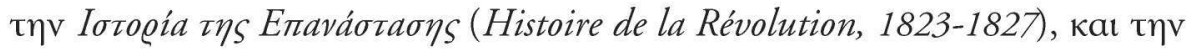

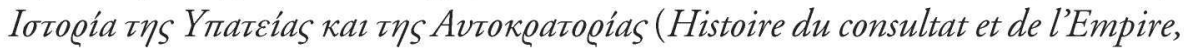

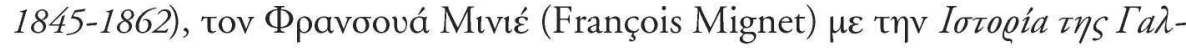

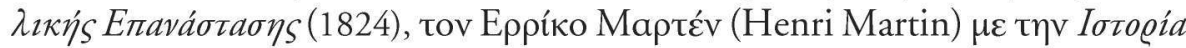

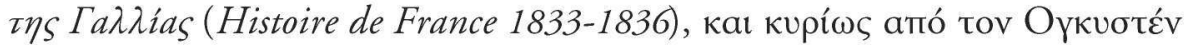

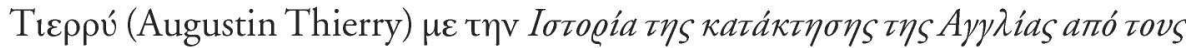
Nopuavoov́s (Histoire de la conquête de l'Angleterre par les Normands, 1825), ta

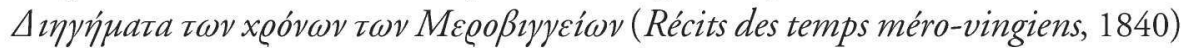

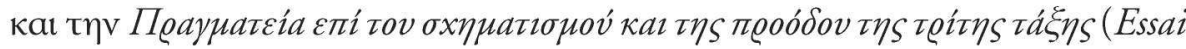
sur l' histoire de la formation et des progrès du tiers état, 1850), $\eta$ totopía ouví-

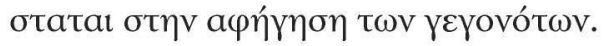

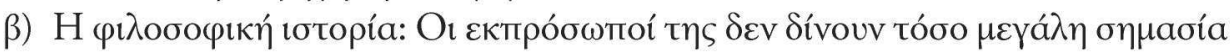

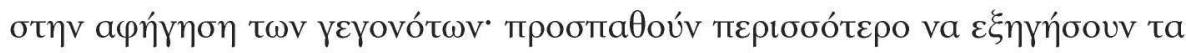

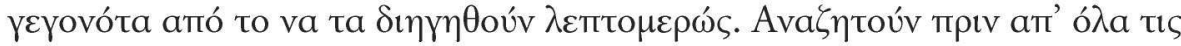

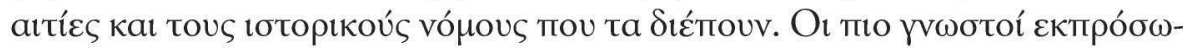

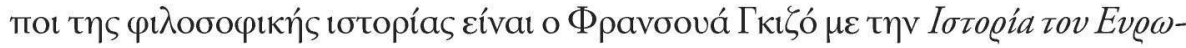

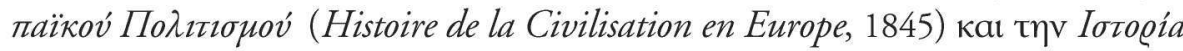

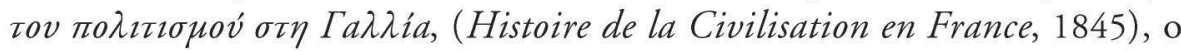

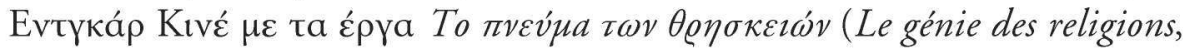

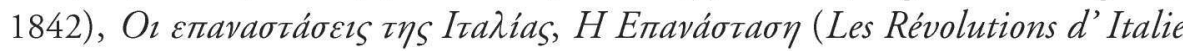

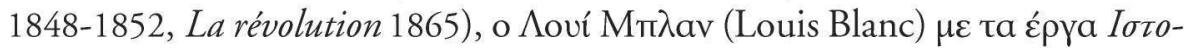

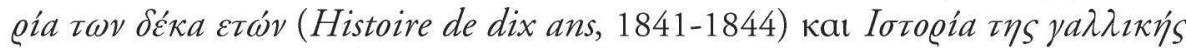

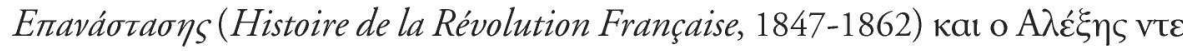

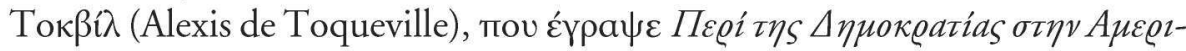

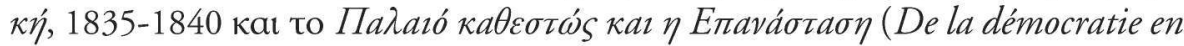
Amérique, 1835-1840, L'Ancien régime et la Révolution, 1856).

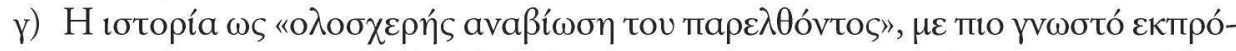

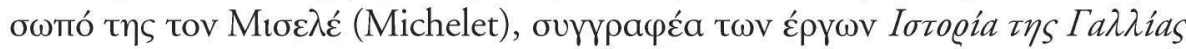

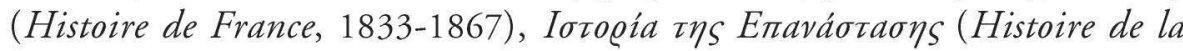

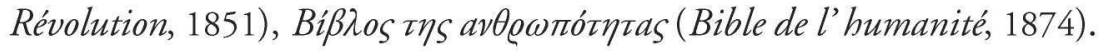

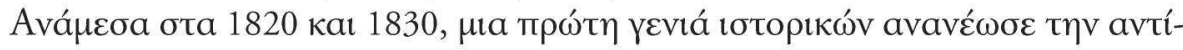

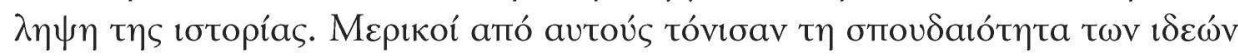

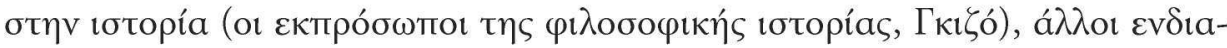

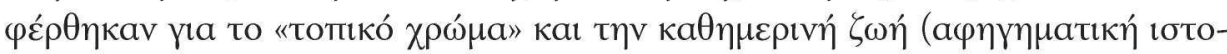

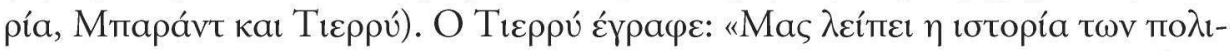

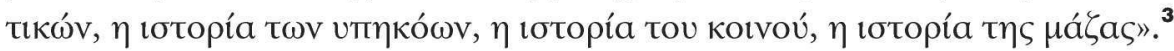

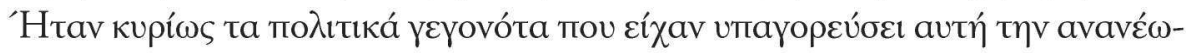




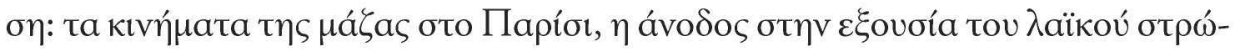

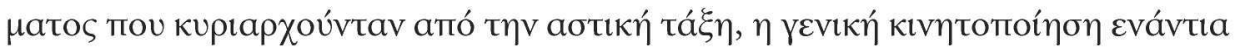

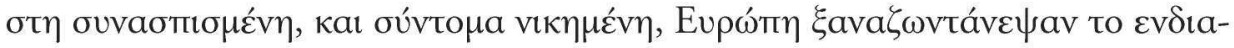

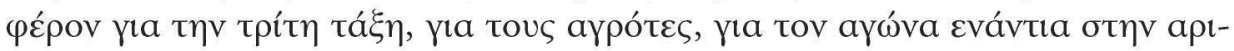

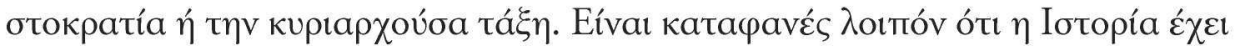

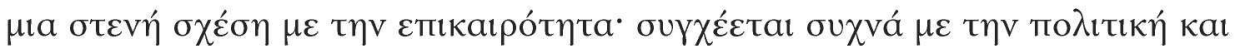

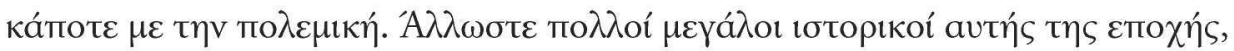

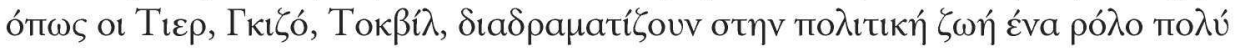

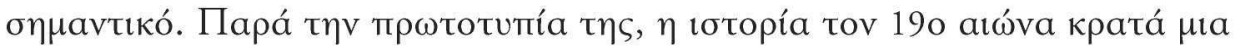

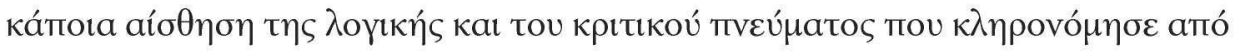

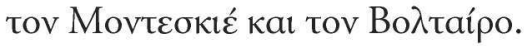

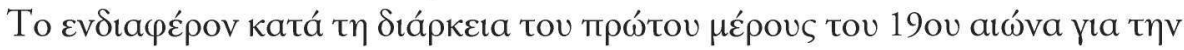

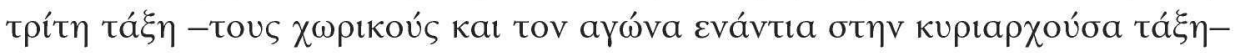

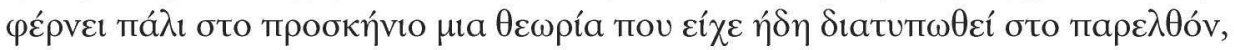

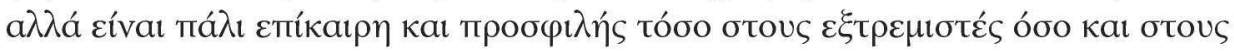

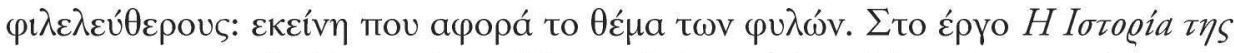

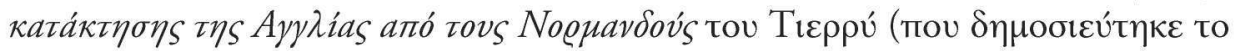

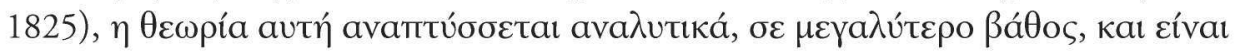

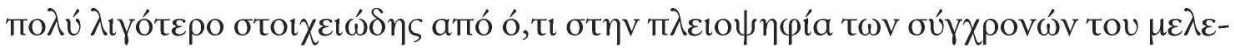

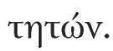

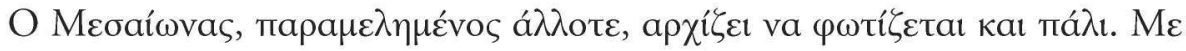

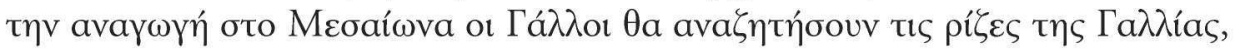

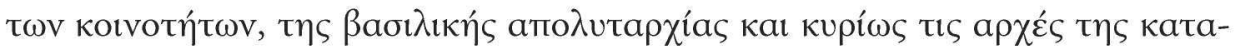

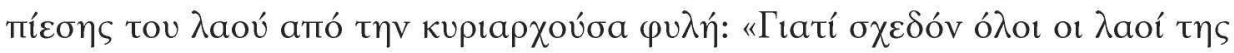

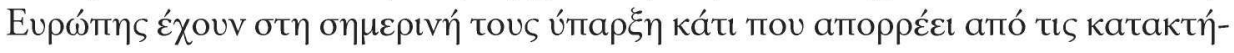

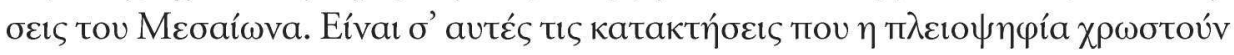

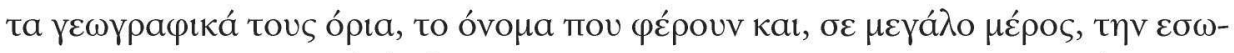

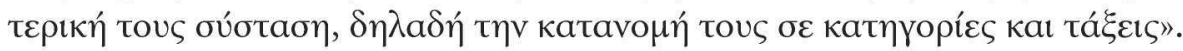

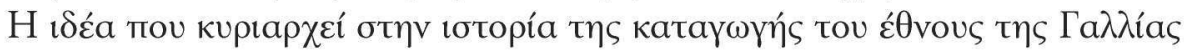

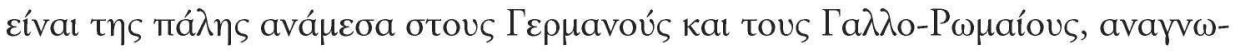

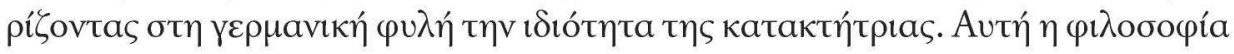

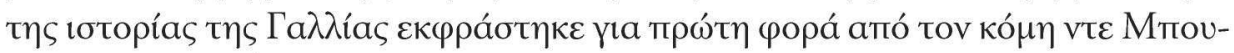
$\lambda \varepsilon v \beta \iota \lambda_{t} \varepsilon \dot{\varepsilon}(1732){ }^{4}$

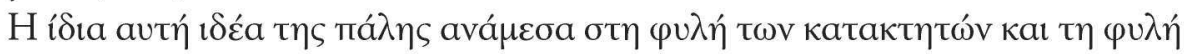

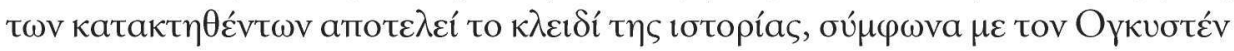

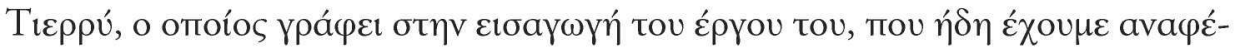

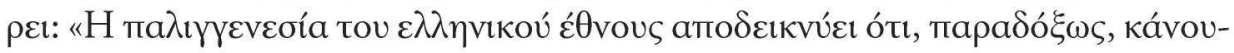




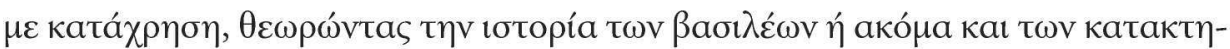

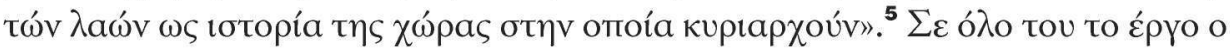

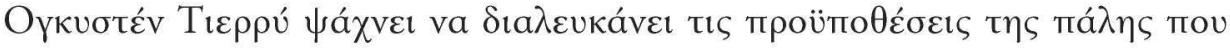

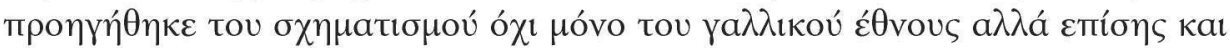

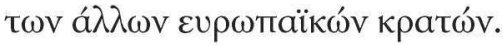

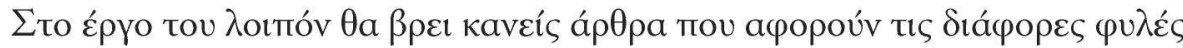

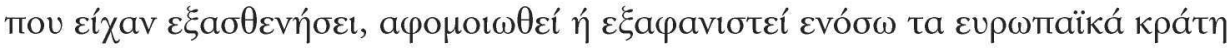

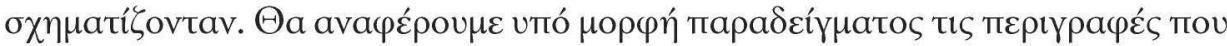
a

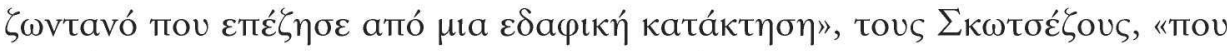

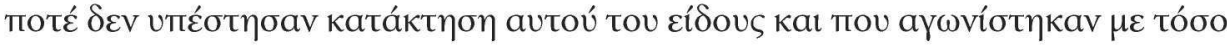

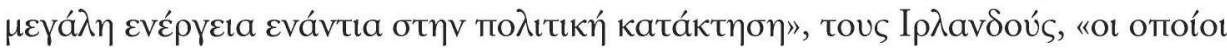

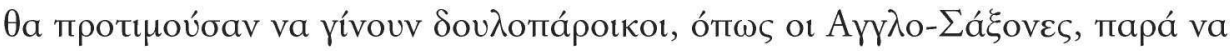

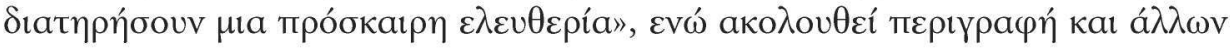

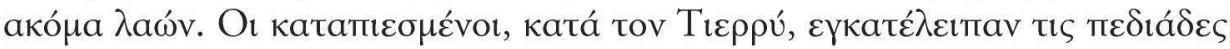

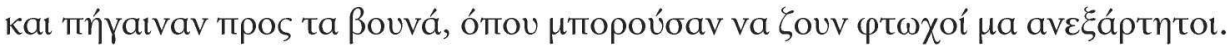

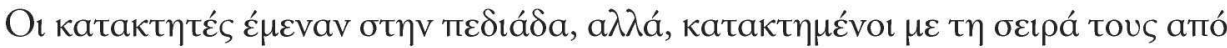

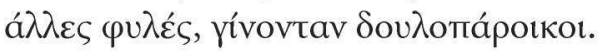

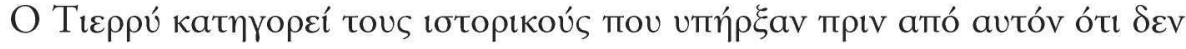

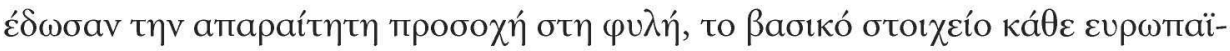

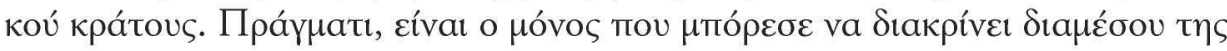

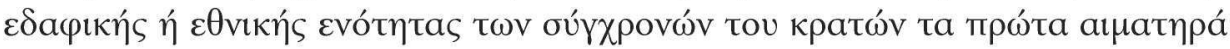

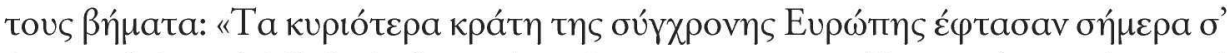

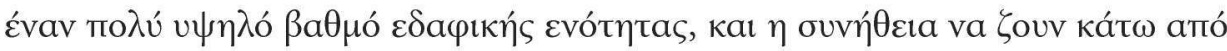

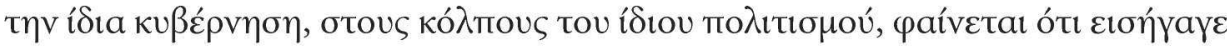

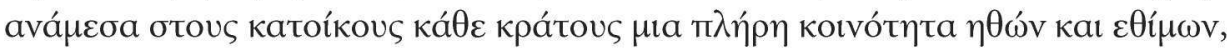

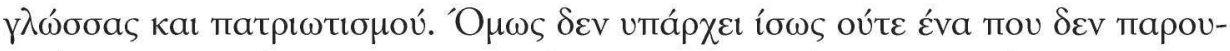

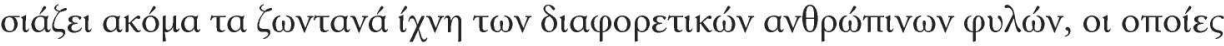

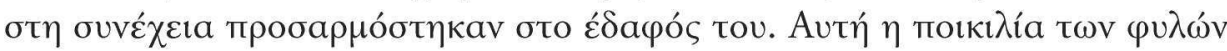

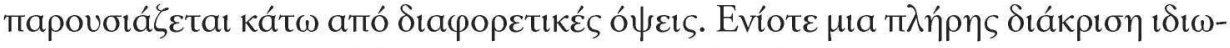

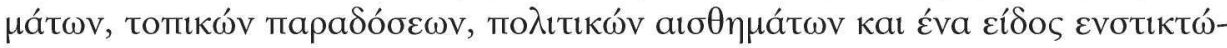

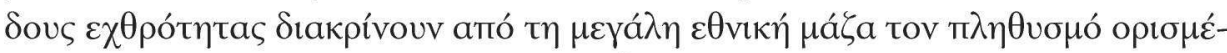

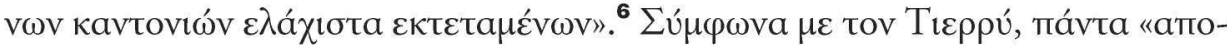

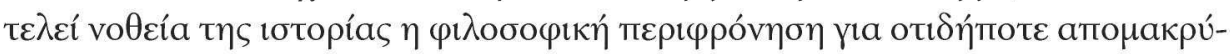

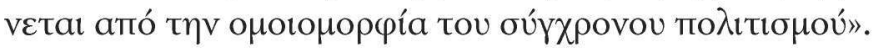

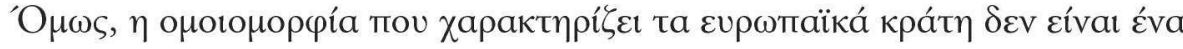

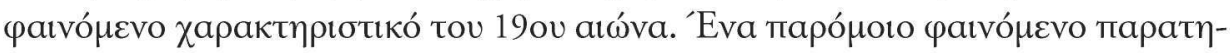




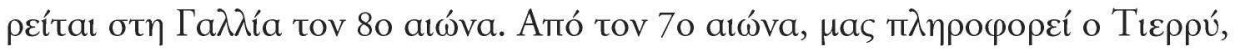

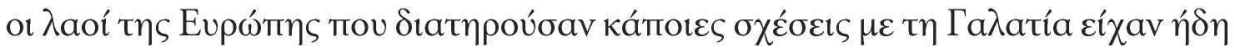

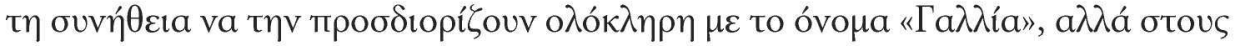

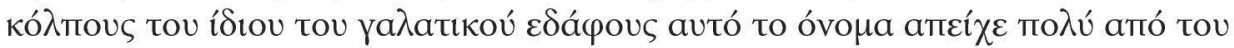

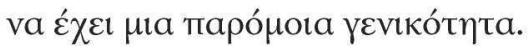

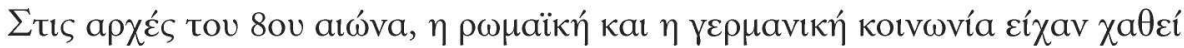

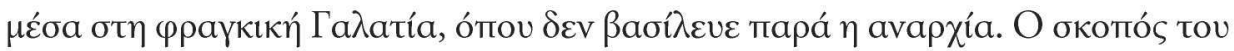

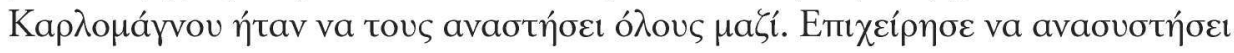

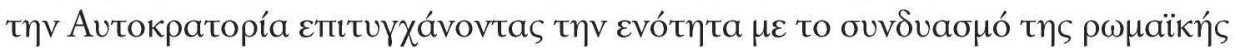

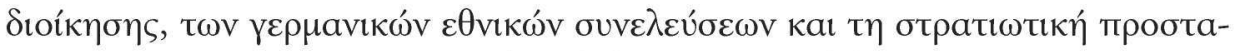

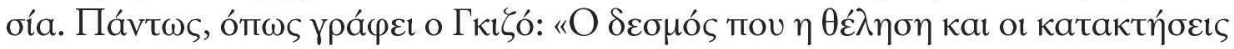

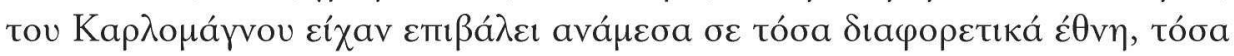

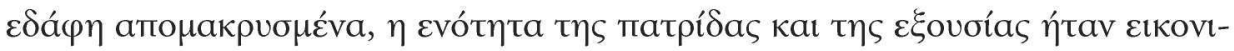

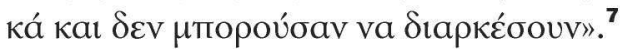

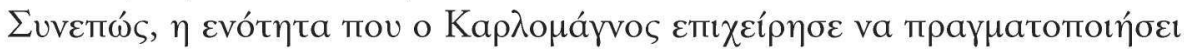

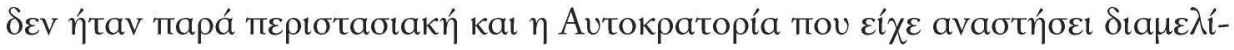

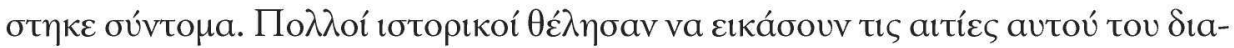

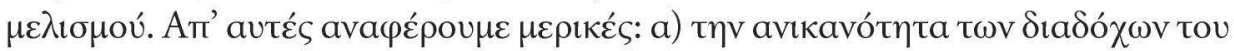

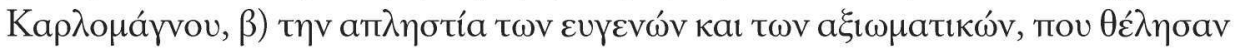

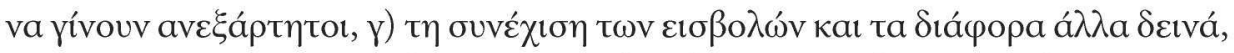

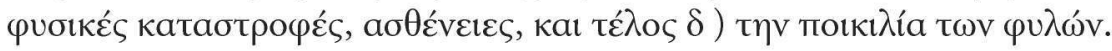

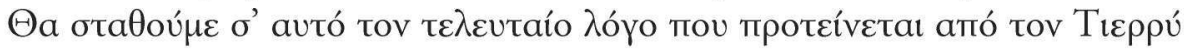

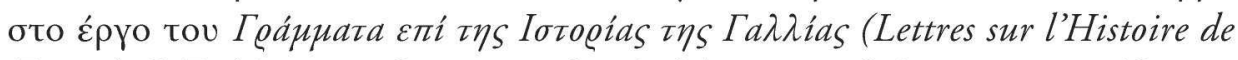

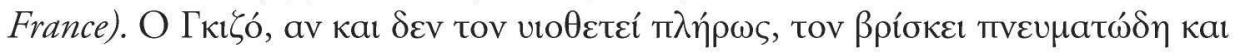

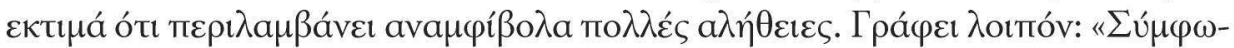

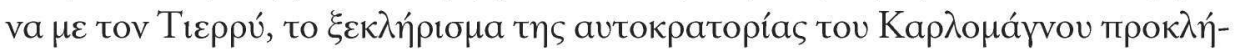

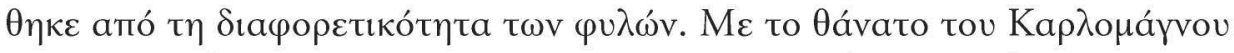

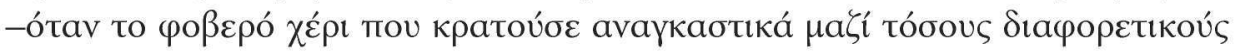

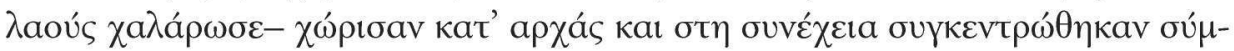

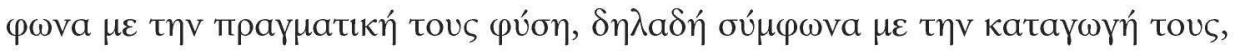

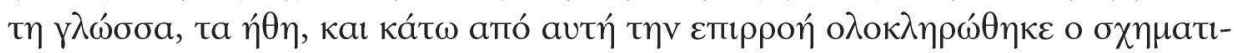

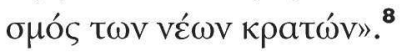

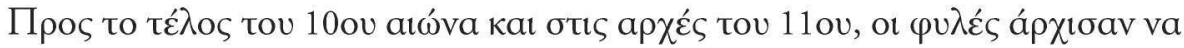

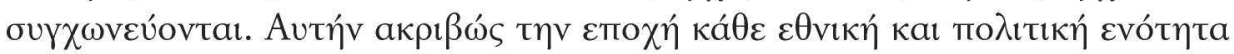
$\varepsilon \xi$ a

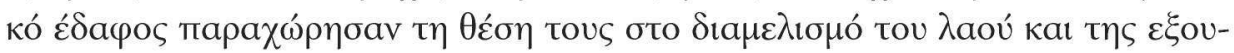

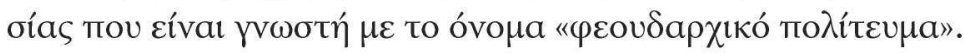




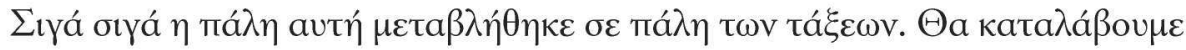

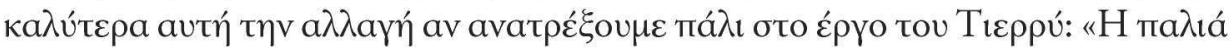

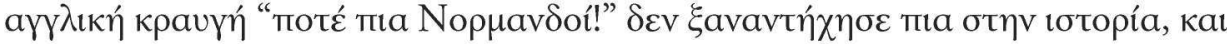

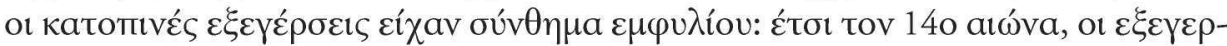

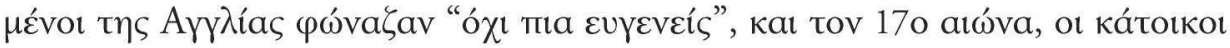

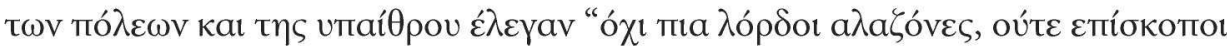

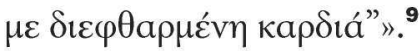

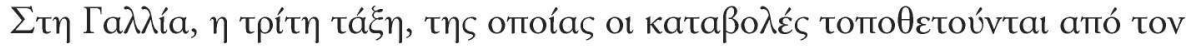

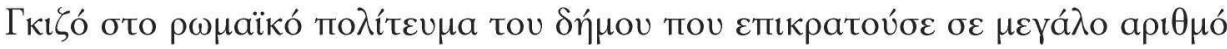

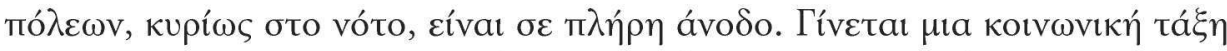

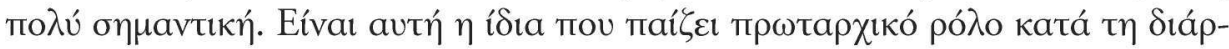

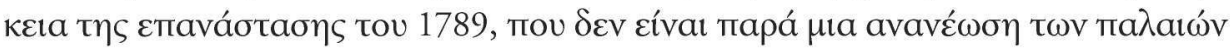

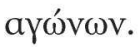

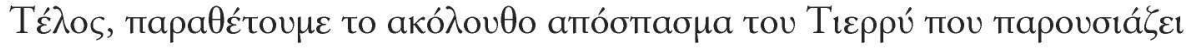

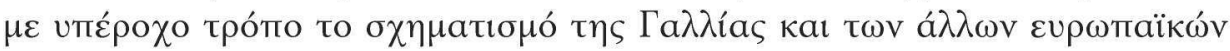

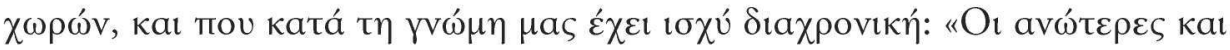

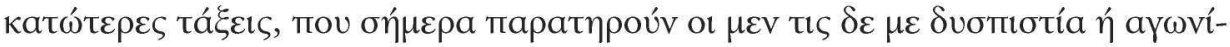

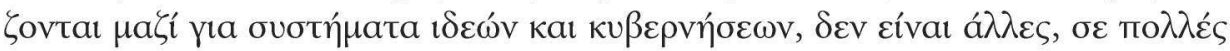

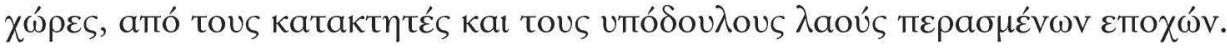

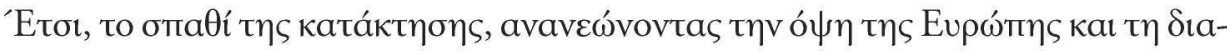

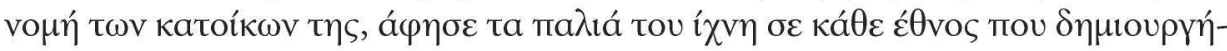

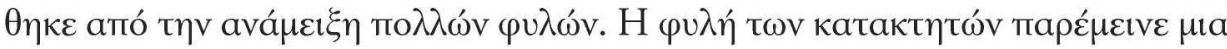

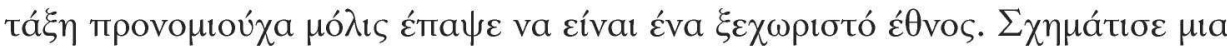

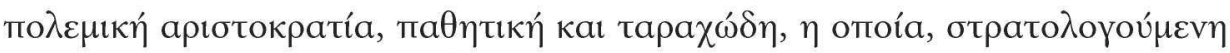

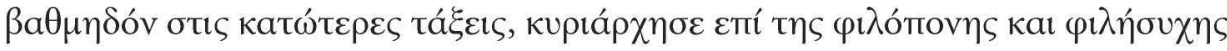

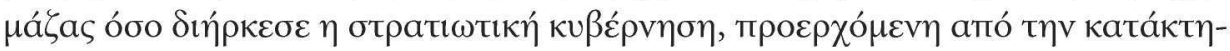

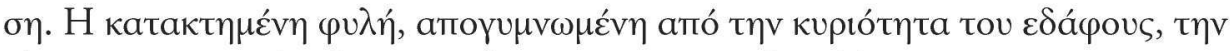

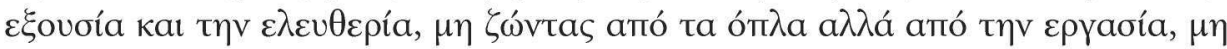

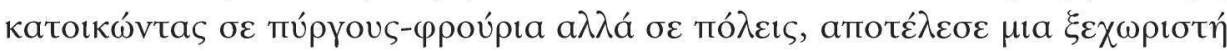

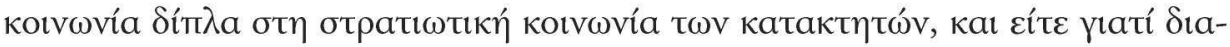

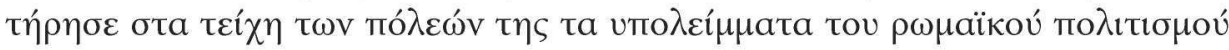

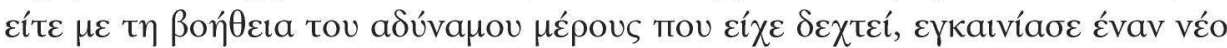

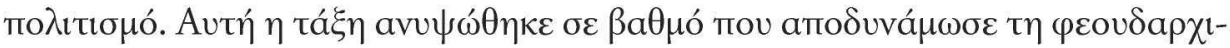

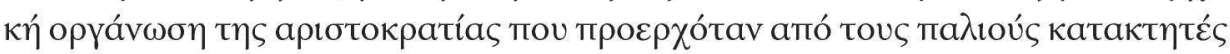

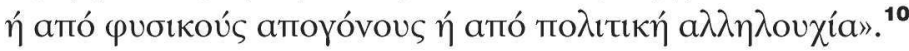

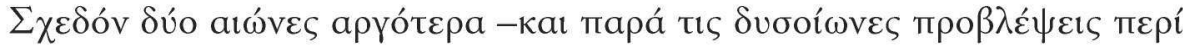

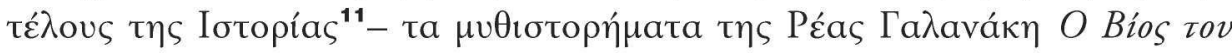




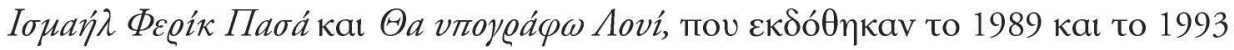

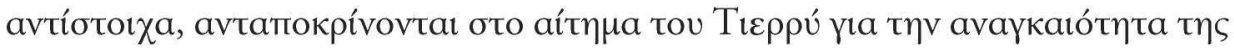

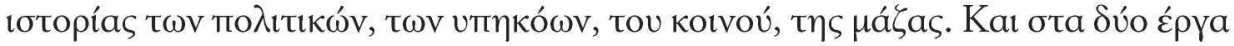

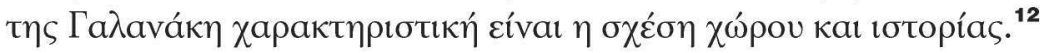

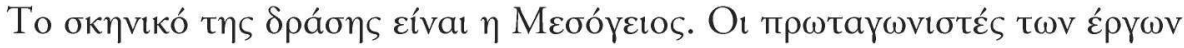

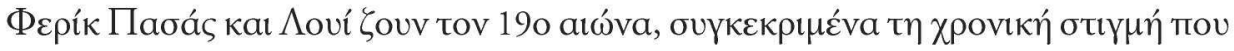

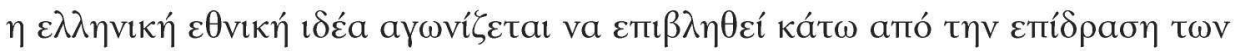

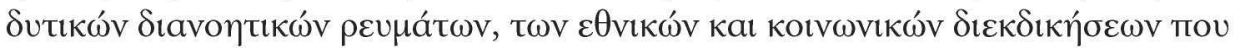

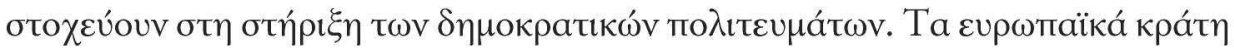

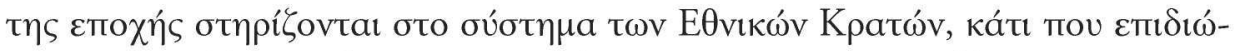

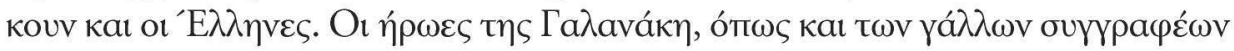

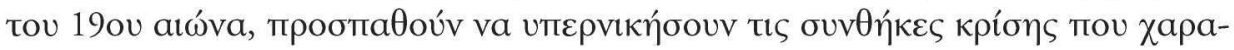

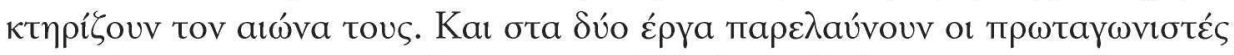

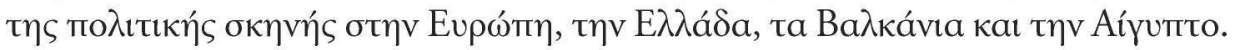

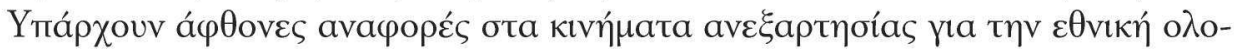

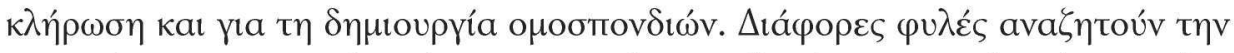

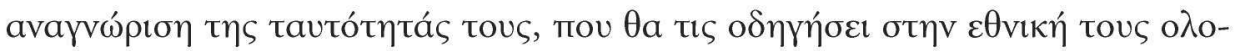

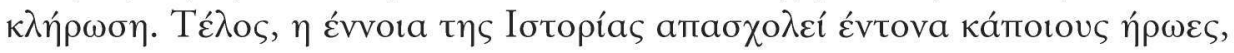

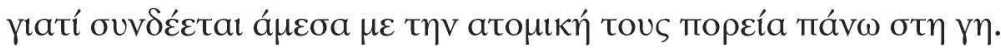

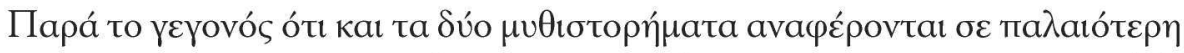

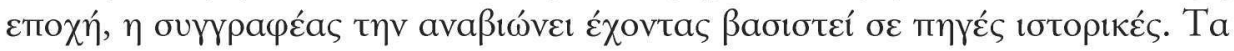

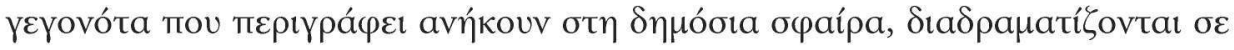

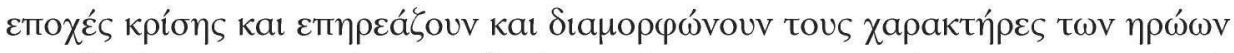

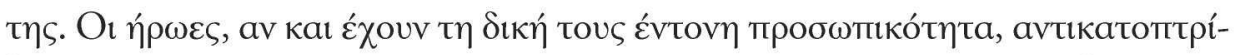

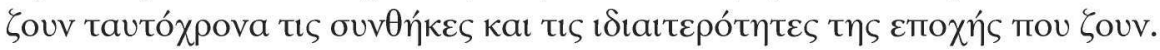

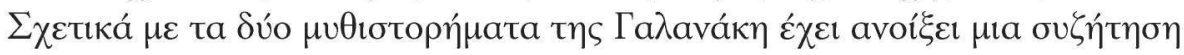

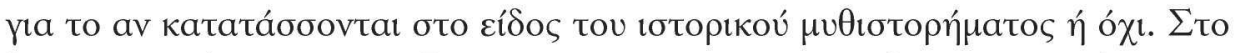

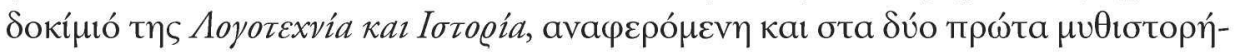

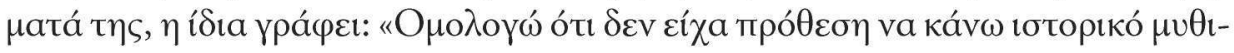

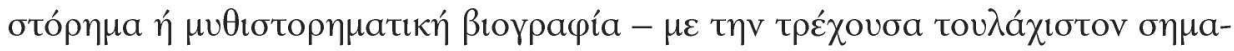

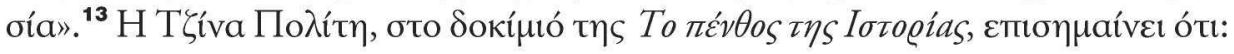

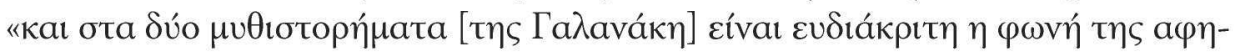

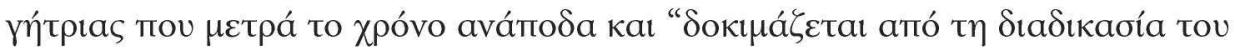

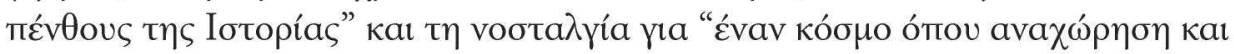

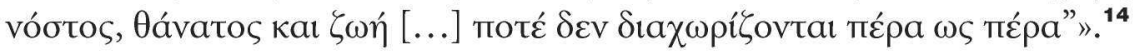

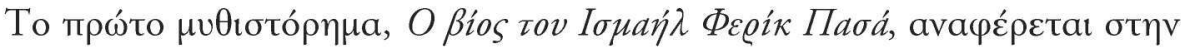

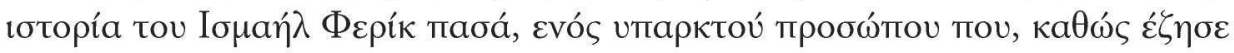




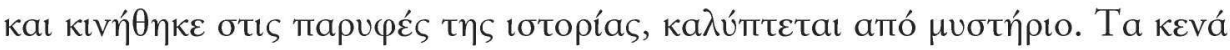

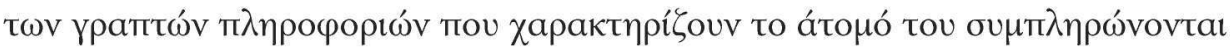

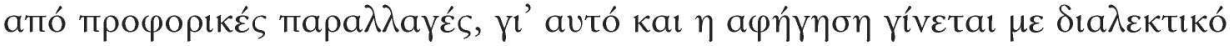

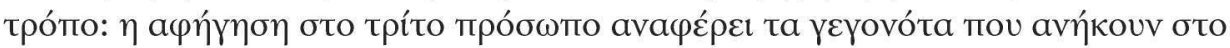

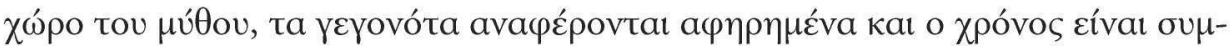

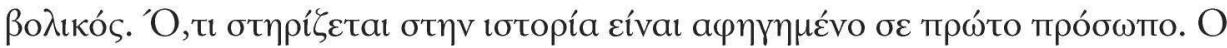

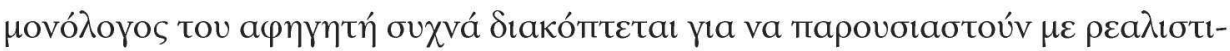

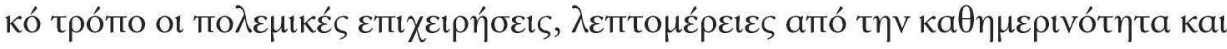

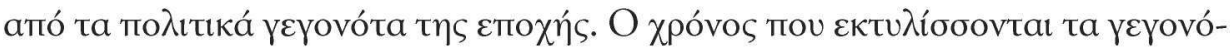

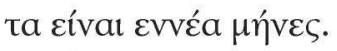

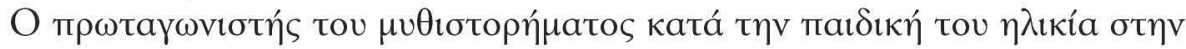

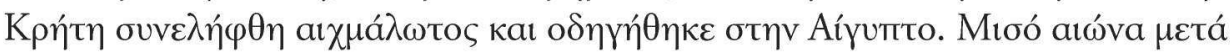

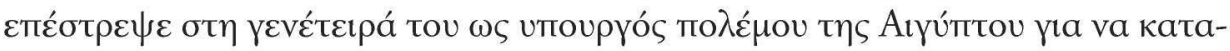

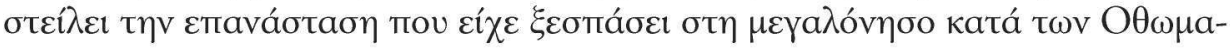

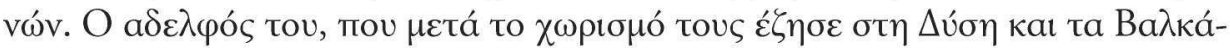

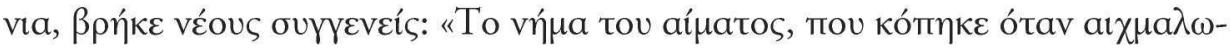

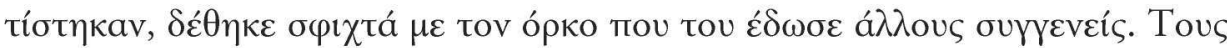

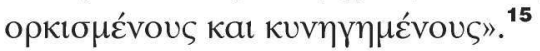

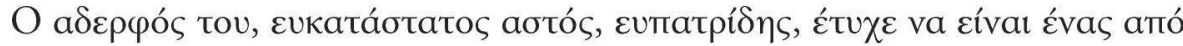

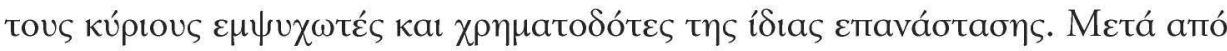

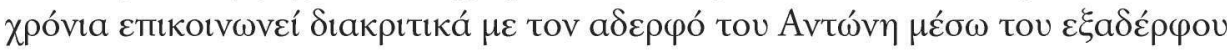

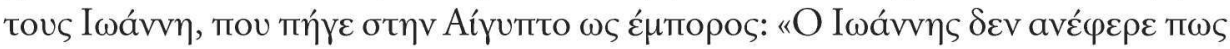

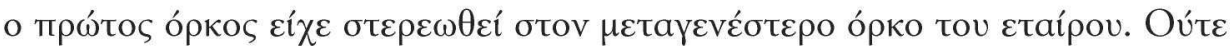

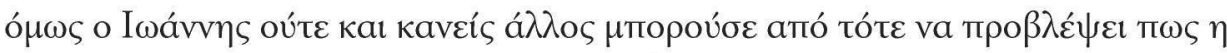

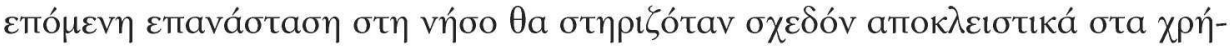

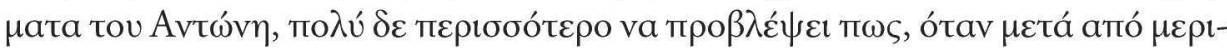

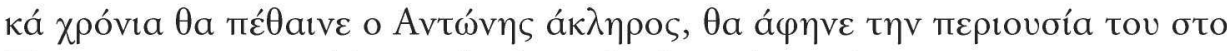

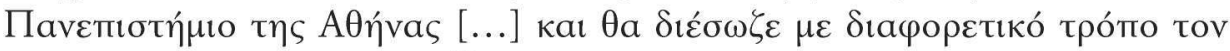

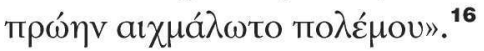

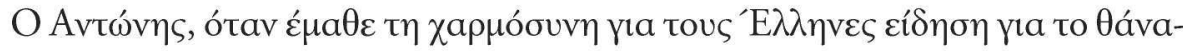

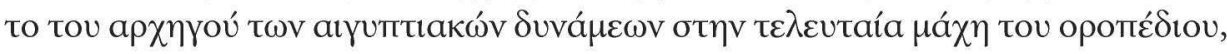

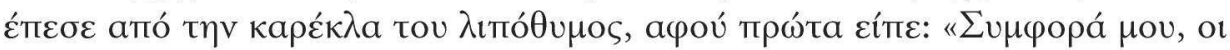

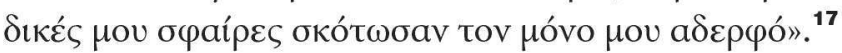

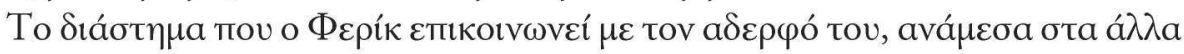

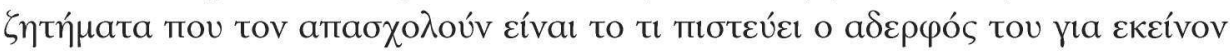

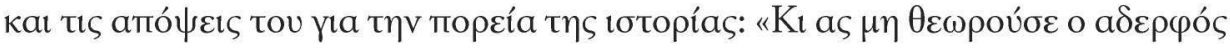

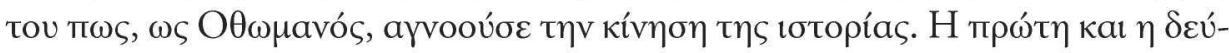




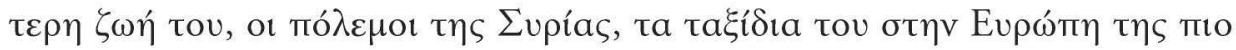

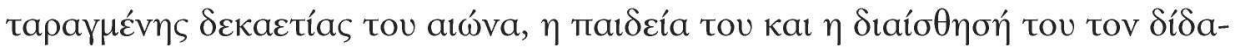

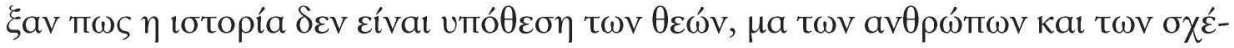

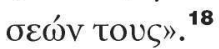

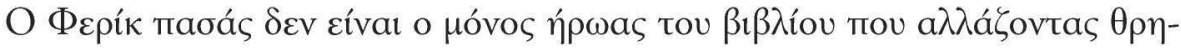

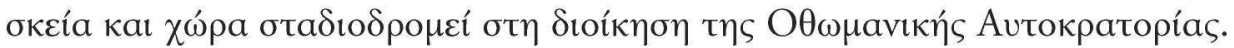

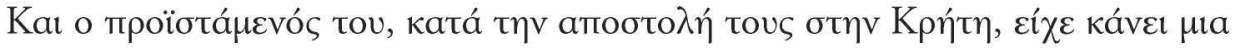

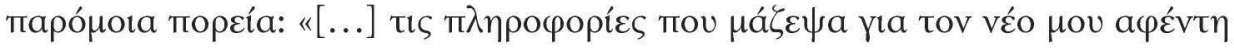

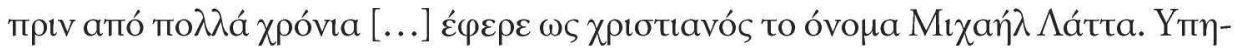

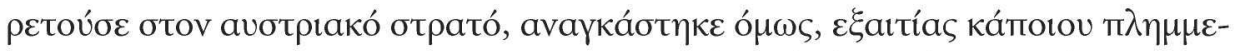

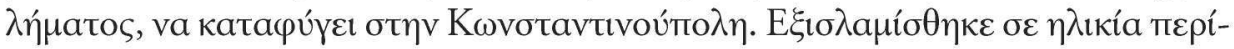

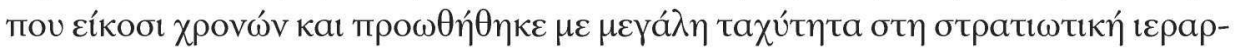

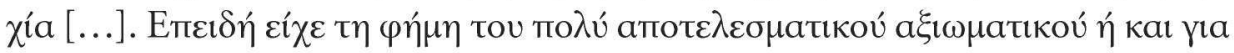

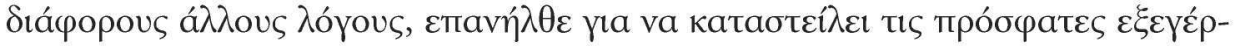

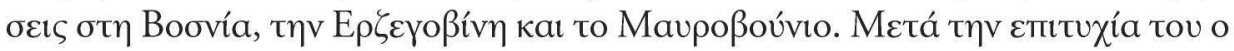

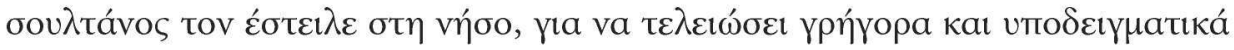

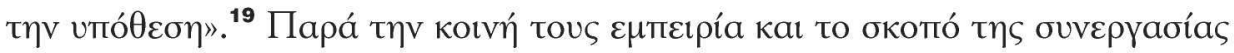

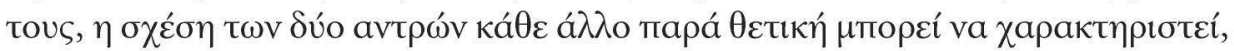

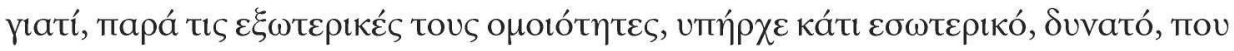

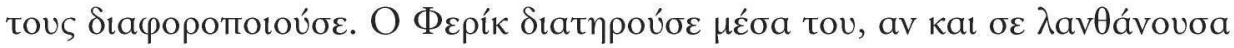

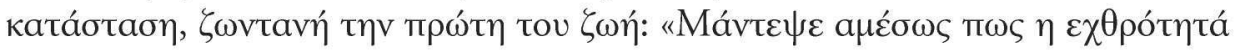

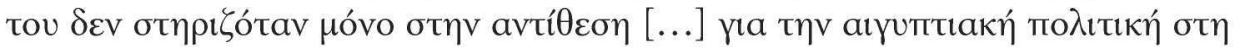

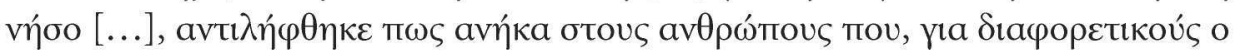

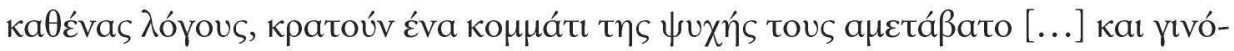

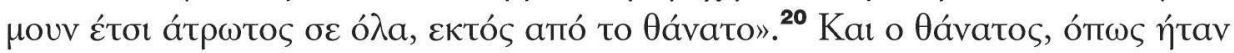

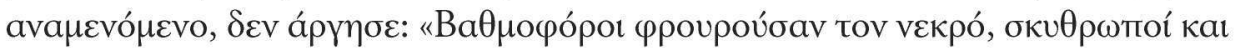

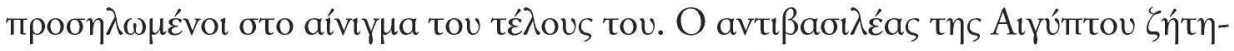

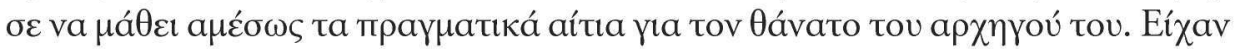

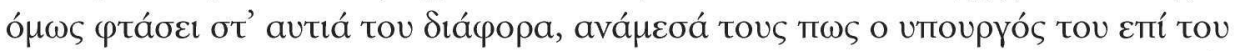

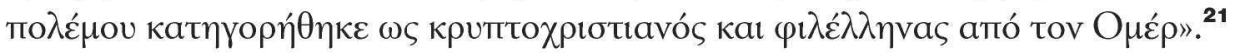

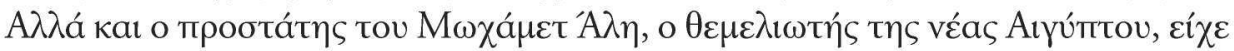

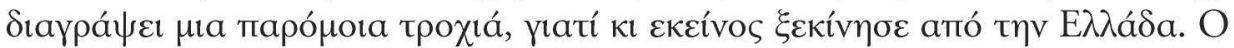

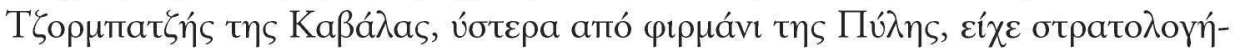

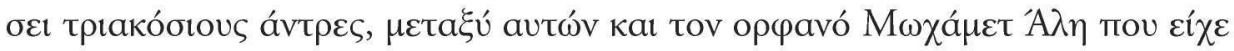

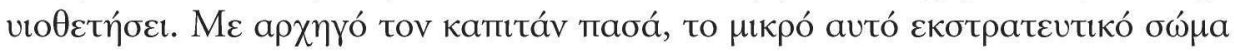

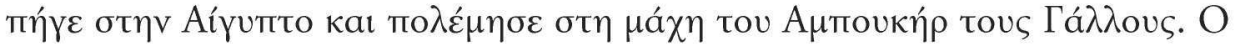

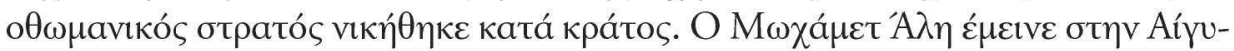




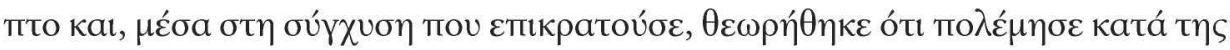

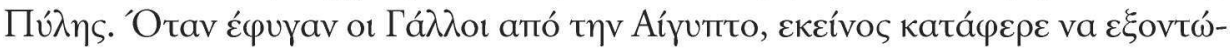

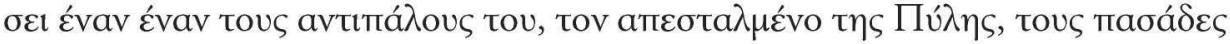

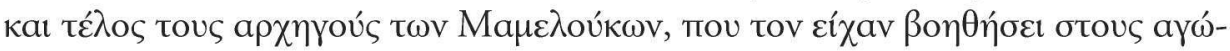

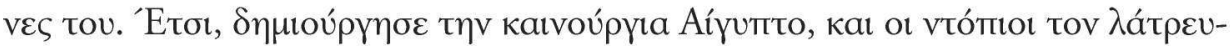

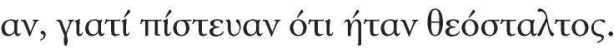

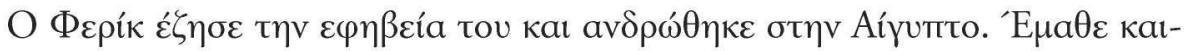

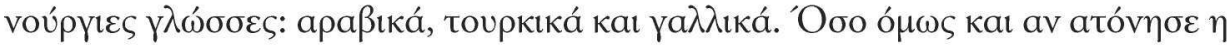

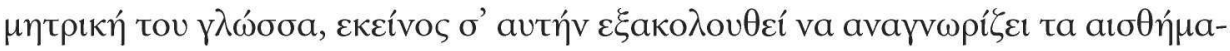

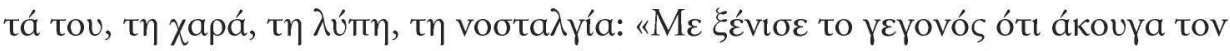

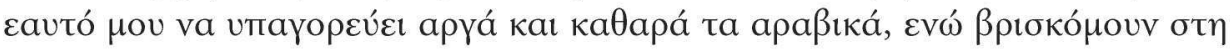

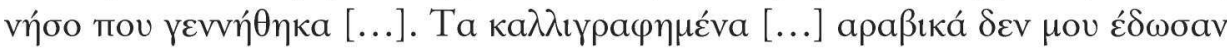

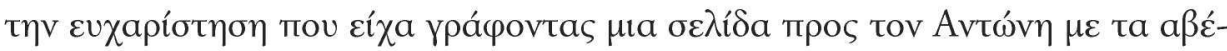

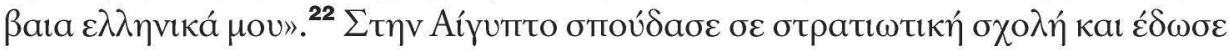

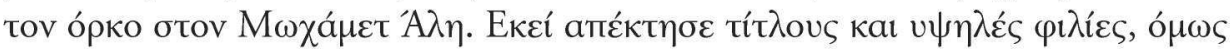

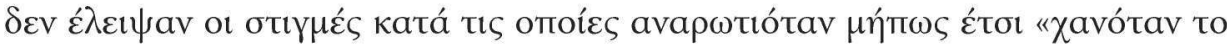

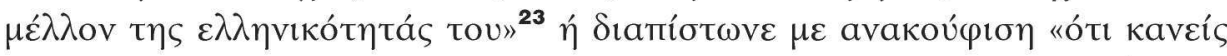

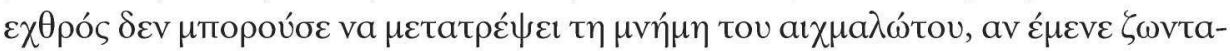

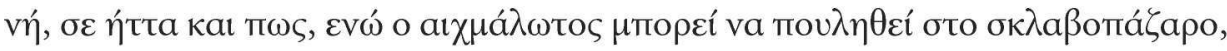

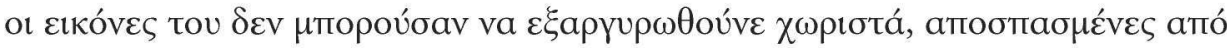
то $\sigma \omega ́ \mu \alpha$ tou». ${ }^{24}$

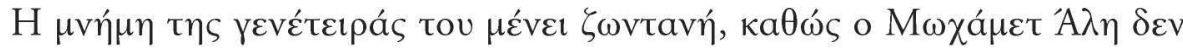

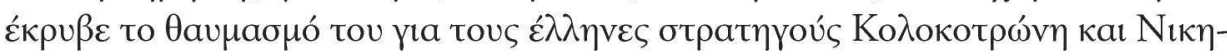

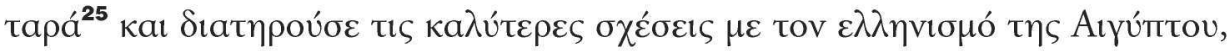

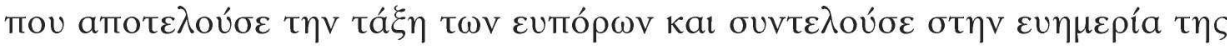

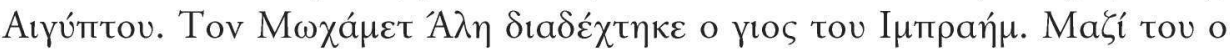

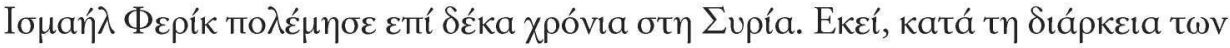

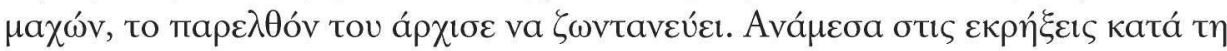

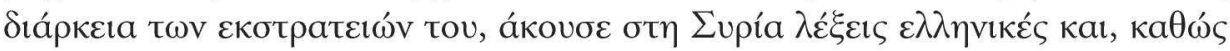

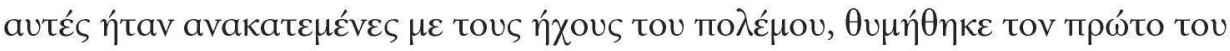

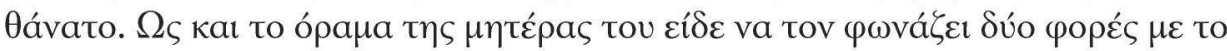

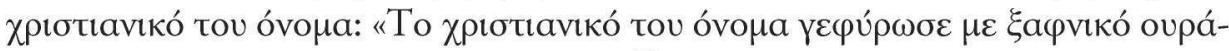

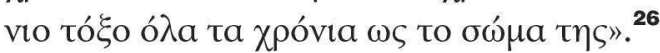

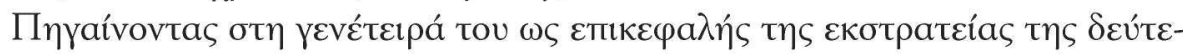

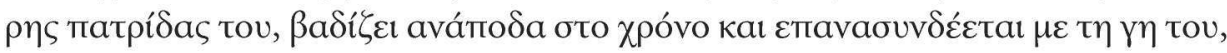

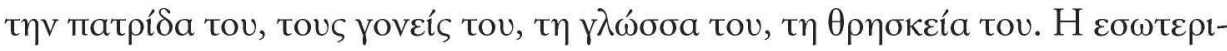

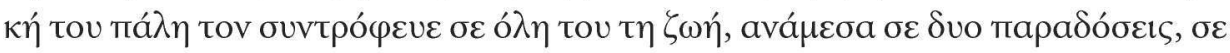




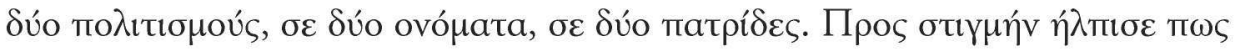
$\theta a$ ката́

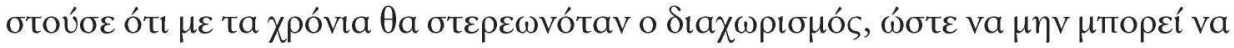

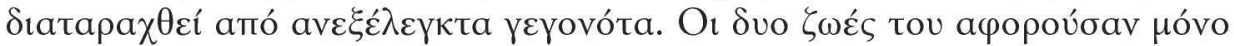

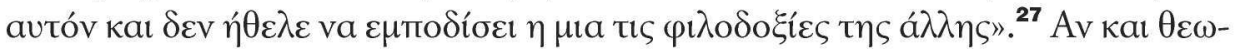

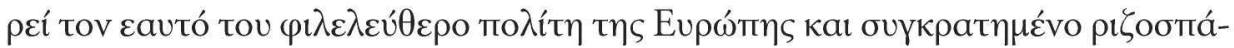

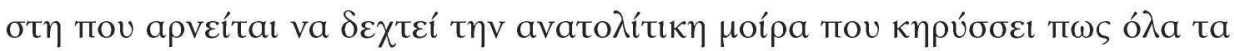

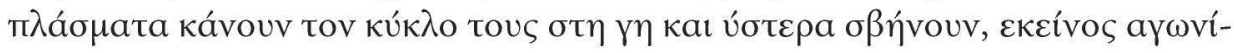

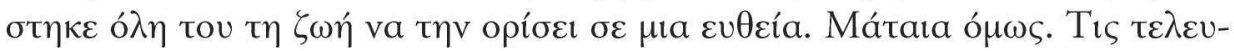

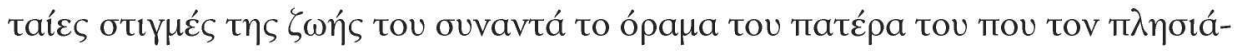
$\zeta \varepsilon t \psi \varepsilon \dot{\lambda} \lambda$ vovtas.

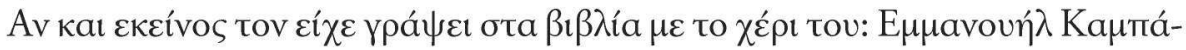

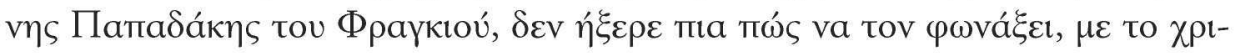

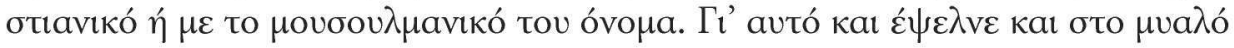

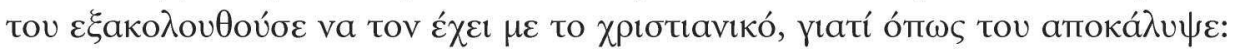

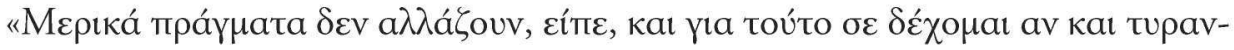

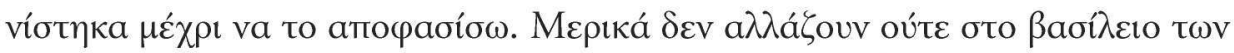

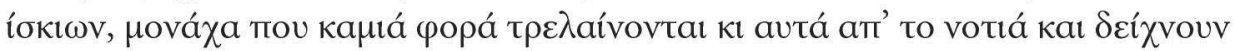

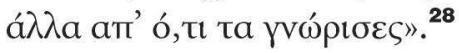

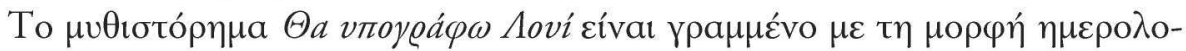

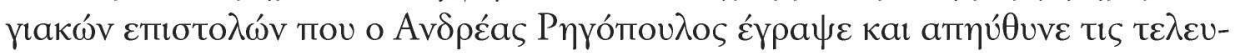

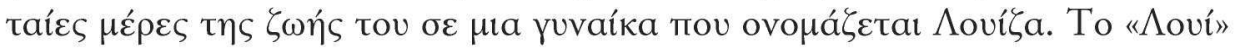

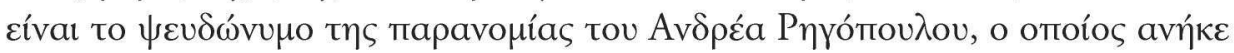

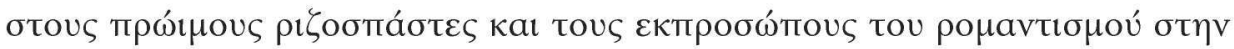

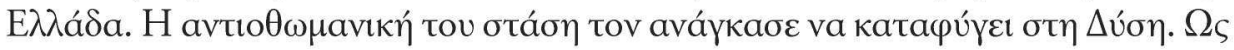

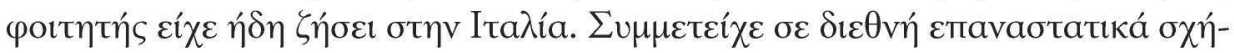

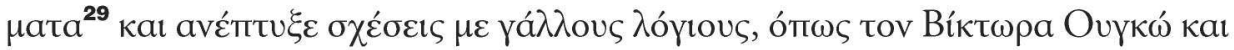
Tov Еvтүкáp Kivé. ${ }^{30}$

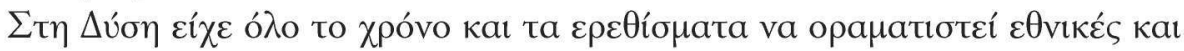

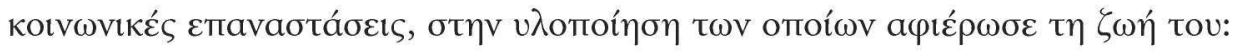

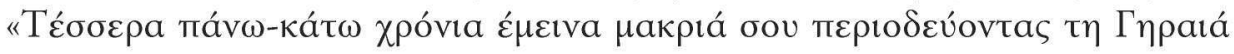

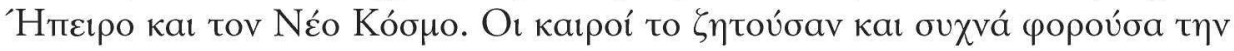

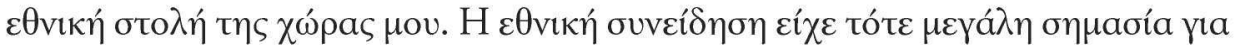

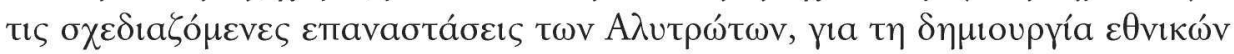

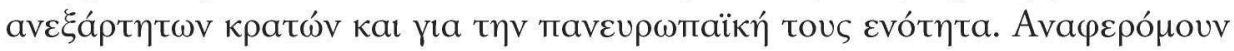

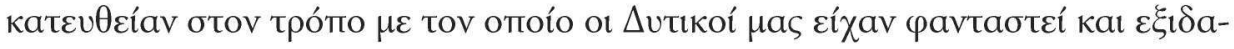

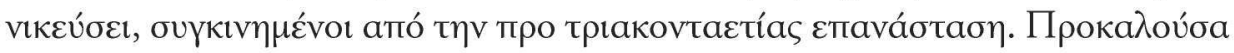




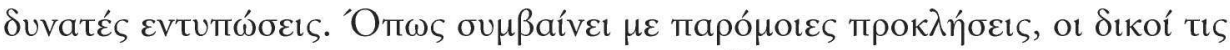

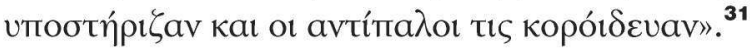

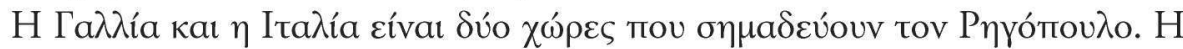

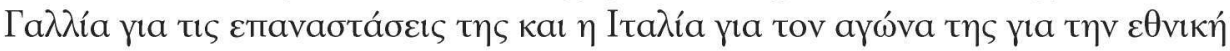

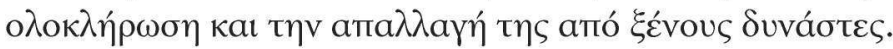

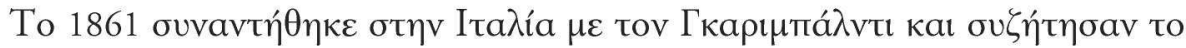

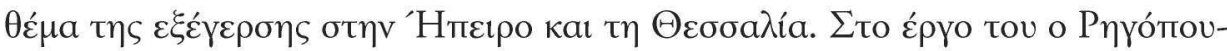

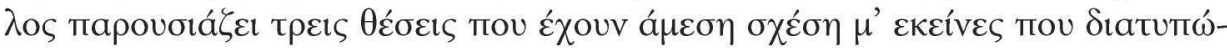

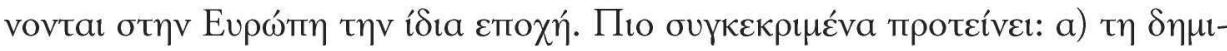

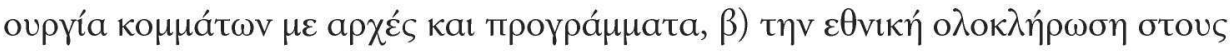

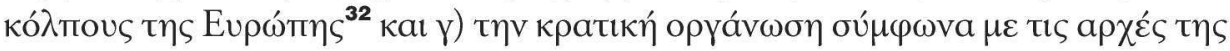

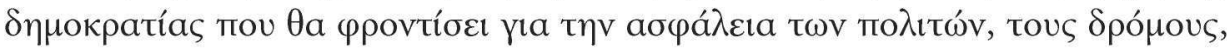

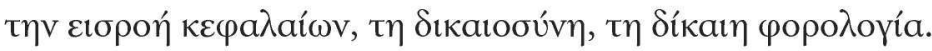

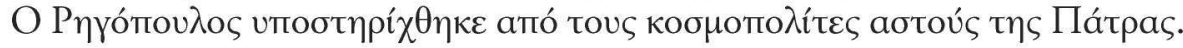

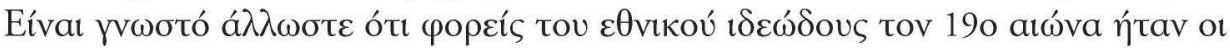

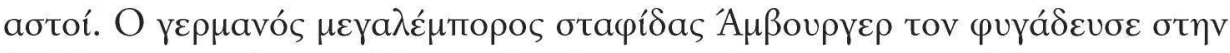

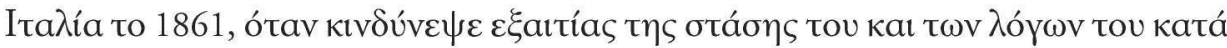

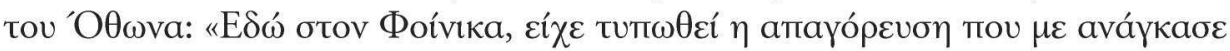

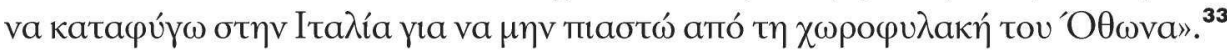

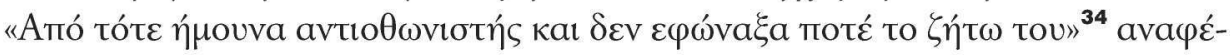

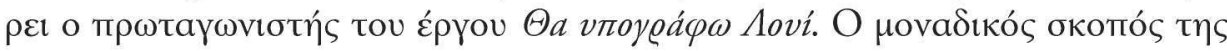

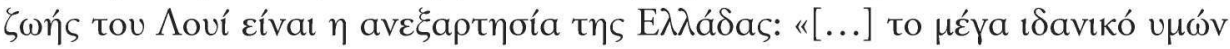

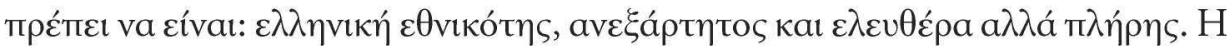

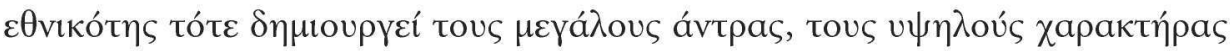

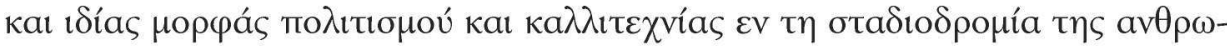

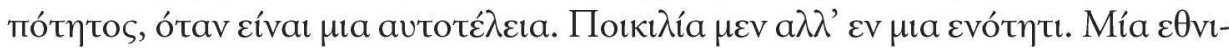

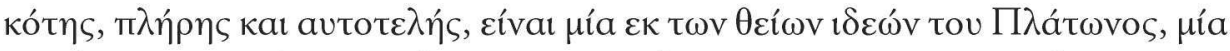

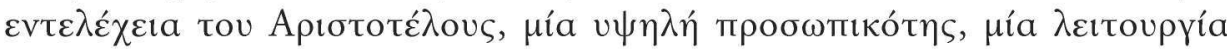

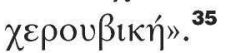

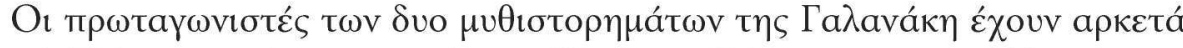

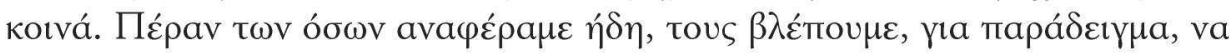

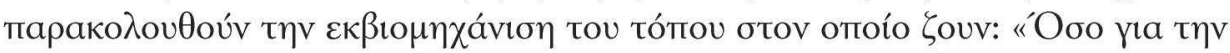

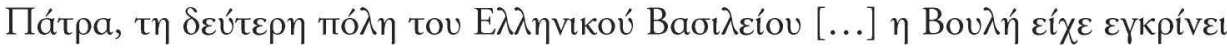

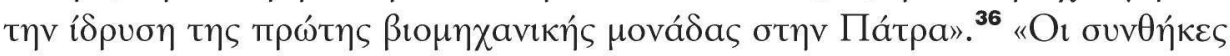

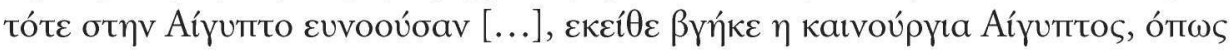

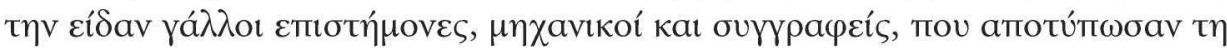

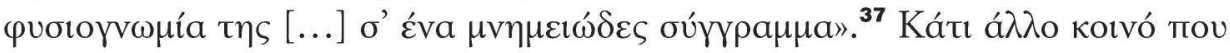




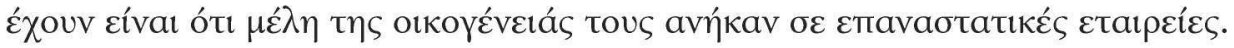

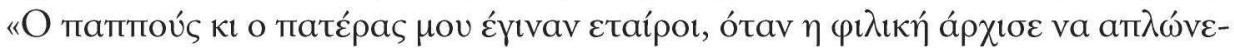

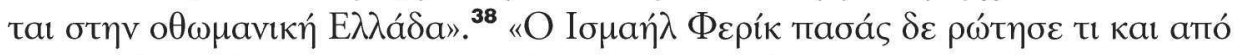

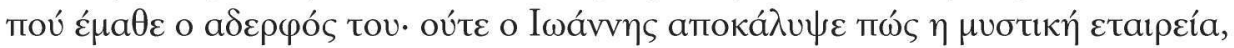

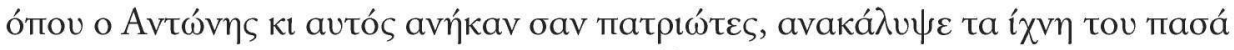

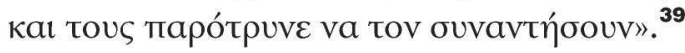

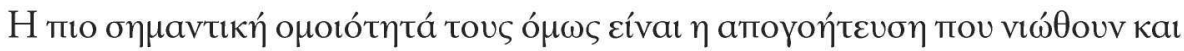

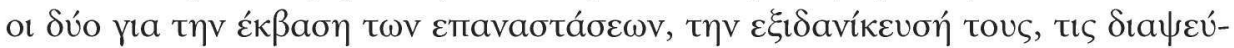

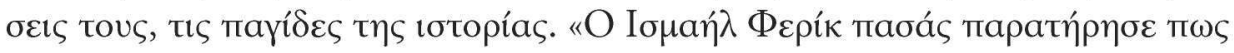

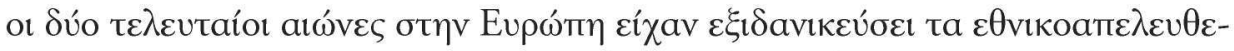

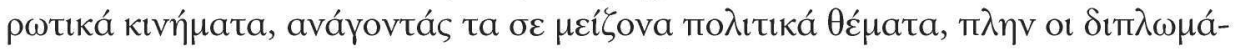

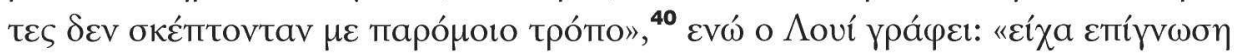

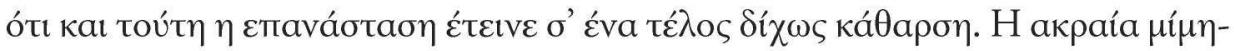

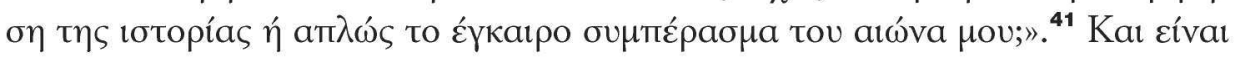

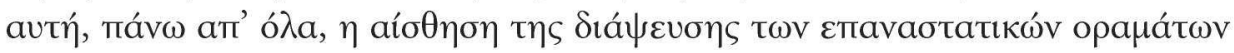

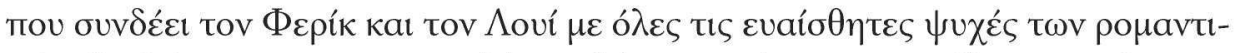

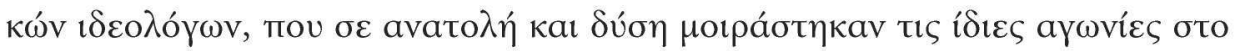

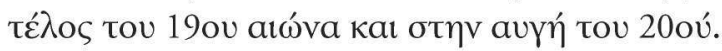

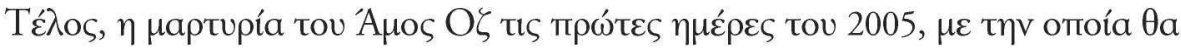

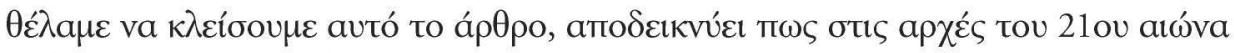

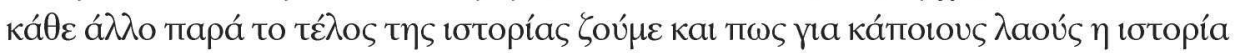

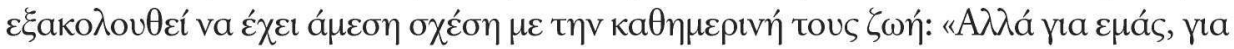

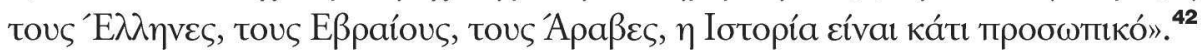

\section{$\Sigma H M E I \Omega \Sigma E I \Sigma$}

1 Augustin Thierry, Recits des Temps Merovingiens, introduction de Robert Delort, Paris, L' arbre double, Les Presses d'Aujourd'hui, 1981, б. 8.

2 Augustin Thierry, ó.n., o. 10.

3 Augustin Thierry, Histoire de la conquete de l'Angleterre par les Normands, Paris, Jouvet, 1882 , in 80.

4 Andre Combris, La Philosophie des Races du comte de GOBINEAU et sa portée actuelle. Paris, F. Alcan, 1937, o. 25.
5 O.

$6^{\prime} O . \pi$., тó $\mu .1$, б. 3.

7 François Guizot, Histoire de la civilisation en France depuis la chute de l'Empire romain, Paris, Didier, 1847 , тó

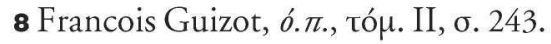

9 Augustin Thierry, ó.n., tó . I, б. 461.

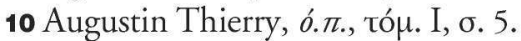

11 O Francis Fukuyama avaфépeı tov

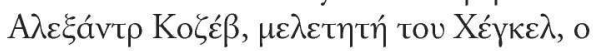




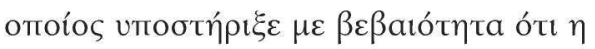

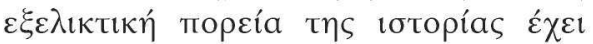

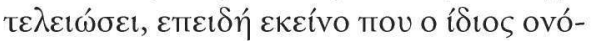

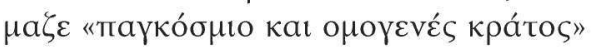

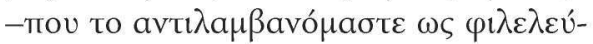

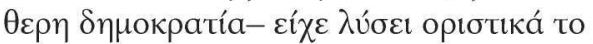
тро́ $\beta \lambda \eta \mu а ~ т \eta s ~ a v a \gamma v \omega ́ \rho t \sigma \eta s, ~ a v т t к a \theta_{-}$

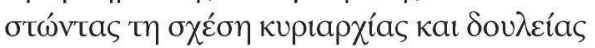

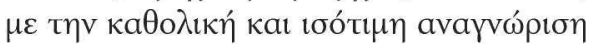

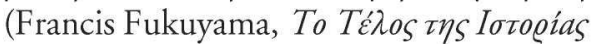

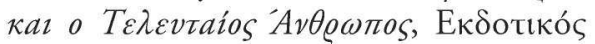

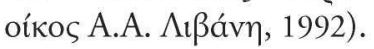

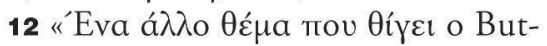

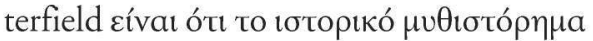

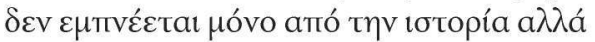

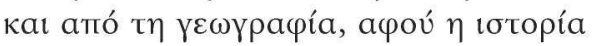

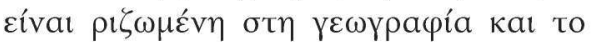

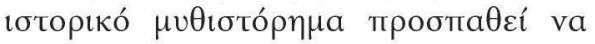

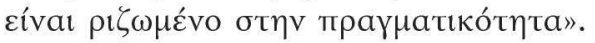

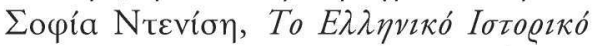

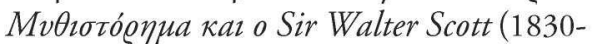

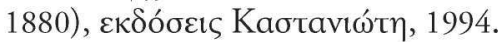

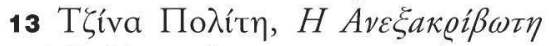

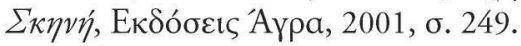

$14^{\prime} O . \pi .$, б. 236.

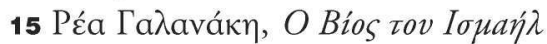

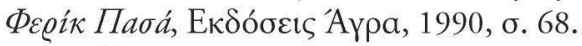

16 O. $\pi .$, б. 61.

$17^{\prime} O . \pi .$, б. 191.

18 O. $\pi ., \sigma .75$.

$19^{\prime} O . \pi .$, б $\sigma .140-141$.

$20^{\prime} O . \pi ., \sigma .141$.

$21^{\prime} O . \pi ., \sigma .183$.

22 O. $\pi .$, б. 99.

$23^{\prime} O . \pi ., \sigma .42$.

$24^{\prime} O . \pi ., \sigma .26$.

25 «O

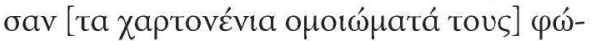

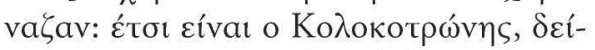

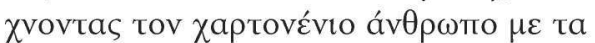

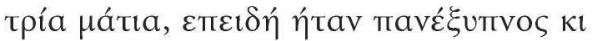

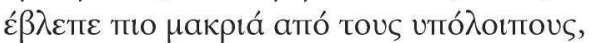

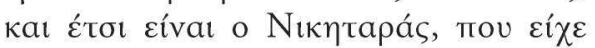

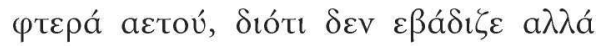

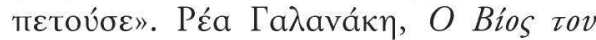

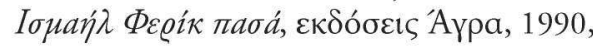
б. 38 .
$26^{\prime} O . \pi .$, б. 38.
$27^{\prime} O . \pi ., \sigma .47$.
$28^{\prime} O . \pi ., \sigma .173$.

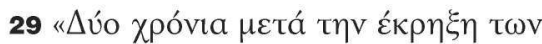

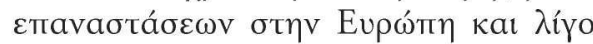

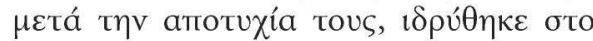

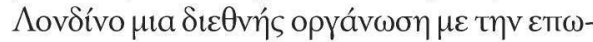

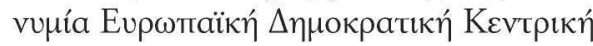

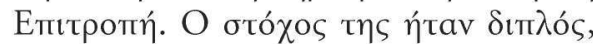

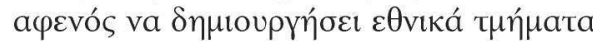

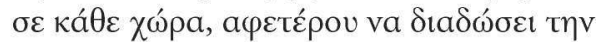

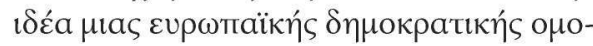

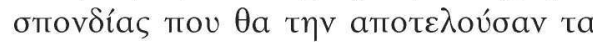

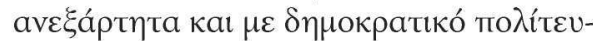

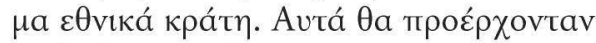

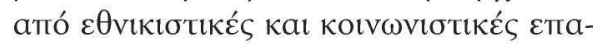

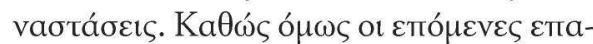

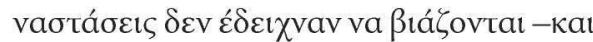

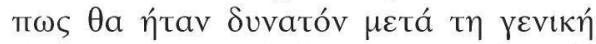

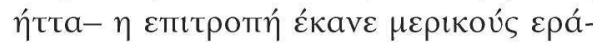

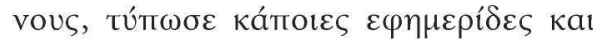

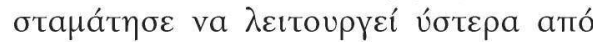
трía xpóvıı.

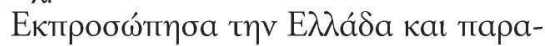

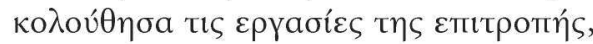

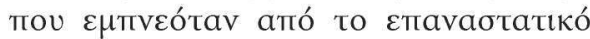

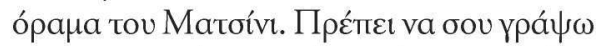

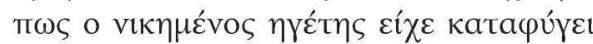

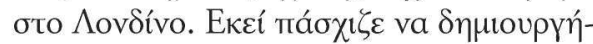

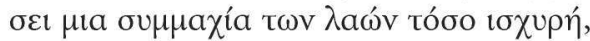

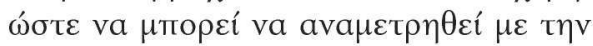

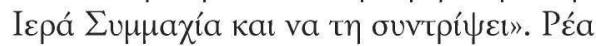

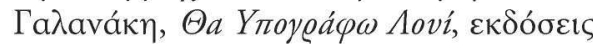
Аүра, 1993, бо. 133 ка 134.

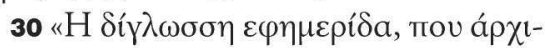

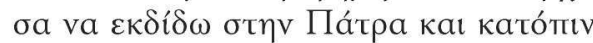

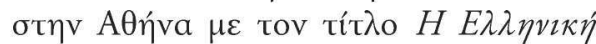

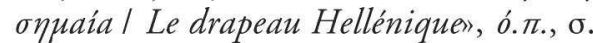

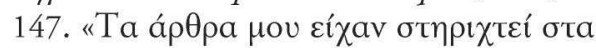




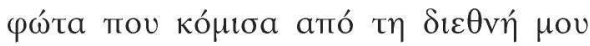

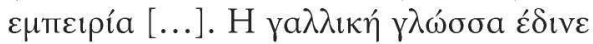

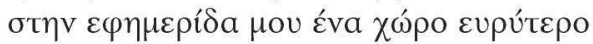

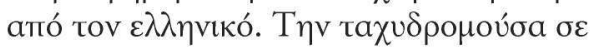

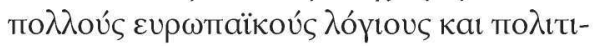

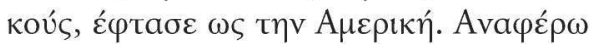

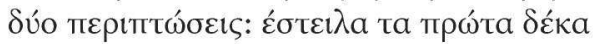

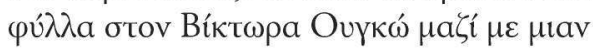

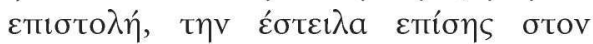

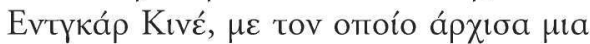

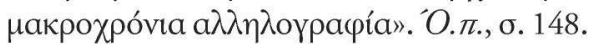

$31^{\prime} O . \pi .$, , 131.

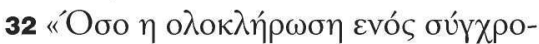

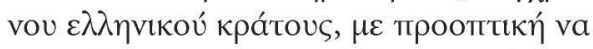

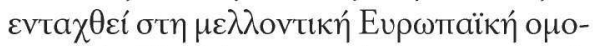

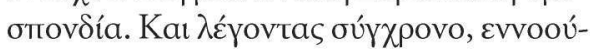

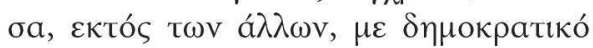

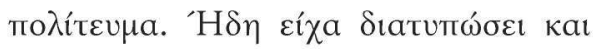

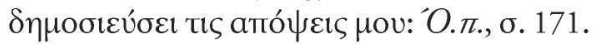

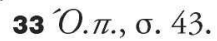

34 'О.

$35^{\prime} O . \pi .$, б. 245.

$36^{\circ} O . \pi .$, , 113.

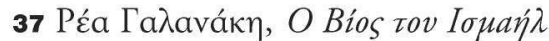

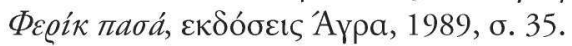

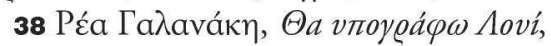

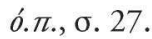

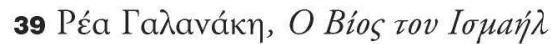

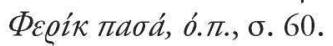

40 O.

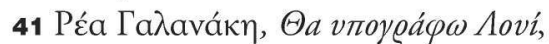
ó. $\pi ., \sigma .221$.

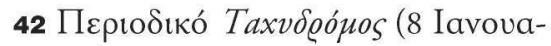
píou 2005).

\section{S O M M A I R E}

AnNA VougioukLidou: Race, la clé de l'Histoire

D ès le début du XIXe siècle la question des nationalités domine toutes les autres en Europe. Influencés par la Révolution française qui a donne aux citoyens français le sentiment qu' ils formaient une communauté nationale, les divers peuples européens ont voulu devenir une nation; pour y arriver ils devaient assurer leur indépendance, qu' ils fussent soumis à un autre Etat ou qu' ils dussent réaliser leur unité lorsqu' ils étaient divisés entre plusieurs Etats. C' est dans le culte de l' Etat, dans le retour aux traditions et surtout dans l' élément de la race que les peuples ont puisé des arguments pour continuer leurs luttes.

La littérature romantique ainsi que l' histoire leur ont fourni un support précieux. Le mouvement des nationalités n' aboutit qu' à des résultats limités. Seules la Grèce et la Belgique ont acquis leur indépendance. Malgré son échec, ce mouvement constitue l' éveil de la conscience nationale des divers peuples et c' est à cet éveil qu' on situe l' origine de l' Europe moderne.

Plusieurs de ces constatations sont visibles dans deux romans grecs écrits par Rea Galanaki: La vie d' Ismael Ferik Pacha et Je signerai Louis parus, presque deux siècles plus tard, en 1989 et en 1993. On peut donc ainsi comprendre l' importance de l' histoire dans la vie des nations et de l' homme lui - même. 